\title{
Article \\ Monitoring Dynamic Recrystallisation in Bioresorbable Alloy Mg-1Zn-0.2Ca by Means of an In Situ Acoustic Emission Technique
}

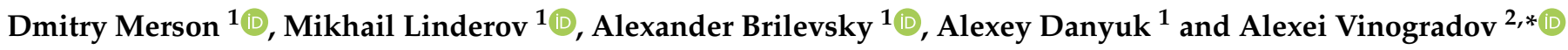 \\ 1 Institute of Advanced Technologies, Togliatti State University, 445020 Togliatti, Russia; \\ D.Merson@tltsu.ru (D.M.); dartvi@gmail.com (M.L.); alexandrbril@yandex.ru (A.B.); \\ alexey.danyuk@gmail.com (A.D.) \\ 2 Department of Mechanical and Industrial Engineering, Norwegian University of Science and Technology, \\ 4791 Trondheim, Norway \\ * Correspondence: alexei.vinogradov@ntnu.no
}

check for updates

Citation: Merson, D.; Linderov, M.; Brilevsky, A.; Danyuk, A.;

Vinogradov, A. Monitoring Dynamic Recrystallisation in Bioresorbable

Alloy Mg- $1 \mathrm{Zn}-0.2 \mathrm{Ca}$ by Means of an In Situ Acoustic Emission Technique. Materials 2022, 15, 328. https:// doi.org/10.3390/ma15010328

Academic Editors: Bertolini Rachele and Mirco Peron

Received: 14 December 2021

Accepted: 30 December 2021

Published: 3 January 2022

Publisher's Note: MDPI stays neutral with regard to jurisdictional claims in published maps and institutional affiliations.

Copyright: (c) 2022 by the authors. Licensee MDPI, Basel, Switzerland. This article is an open access article distributed under the terms and conditions of the Creative Commons Attribution (CC BY) license (https:// creativecommons.org/licenses/by/ $4.0 /)$.

\begin{abstract}
The tensile behaviour of the biocompatible alloy Mg-1Zn-0.2Ca (in wt.\%) in the fine-grained state, obtained by severe plastic deformation via multiaxial isothermal forging, has been investigated in a wide range of temperatures $(20 \div 300){ }^{\circ} \mathrm{C}$ and strain rates $\left(5 \times 10^{-4} \div 2 \times 10^{-2}\right) \mathrm{s}^{-1}$ with the measurements of acoustic emission (AE). The dependences of mechanical properties, including the yield stress, ultimate strength, ductility, and the strain-hardening rate, on the test temperature and strain rate, were obtained and discussed. It is shown for the first time that an acoustic emission method is an effective tool for in situ monitoring of the dynamic recrystallisation (DRX) process. The specific behaviour of the acoustic emission spectral density reflected by its median frequency as a function of strain at various temperatures can serve as an indicator of the DRX process's completeness.
\end{abstract}

Keywords: magnesium alloys; high-temperature deformation; dynamic recrystallisation; acoustic emission; microstructure; mechanical properties

\section{Introduction}

Due to their exceptional properties' profile, magnesium alloys attract burgeoning attention for various applications that span from light vehicle fuel-saving transportation (aerospace, automotive, high-speed rail transport, etc.) to consumable electronics and biomedical devices. The excellent biocompatibility of magnesium and its ability to gradually dissolve in biological media without adverse effects on human tissues opens a potentially massive market for temporary medical structures, such as orthopaedic implants and cardiovascular stents. However, the requirements for biomedical materials are particularly stringent because, besides biocompatibility, non-toxicity, controlled bio-degradability, etc., these materials are supposed to hold the integrity of implanted structures over the whole period of healing, i.e., while providing the necessary mechanical support to healing tissues, they must possess reasonably high resistance to static and dynamic loads in body fluids. These requirements imply that the materials aimed at biomedical applications are supposed to have:

(1) High purity, assuming the absence of toxic or potentially harmful elements that should not enter the human body during the resorption of the implanted structure [1,2].

(2) Sufficiently high strength and ductility, which are conventionally supposed to be better than $250 \mathrm{MPa}$ and 15\%, respectively [3]. High ductility is necessary to achieve the desired products' shape during manufacturing, which traditionally involves metal forming operations. In addition, remaining ductile is a prime requirement for the final product as shape correction and adjustment may be needed during location-specific deployment. 
(3) The controllable (tuneable) rate of bio-corrosion (resorption), which is pivotal for the medical application of magnesium alloys as temporary structures. This rate should be neither too slow nor too fast and comply with the rate of tissue regeneration. Hence, it is commonly assumed to be not worse than $0.5 \mathrm{~mm} /$ year in vivo [3].

Significant efforts invested into the research on biodegradable $\mathrm{Mg}$ alloys are reflected in the growing number of publications (see recent comprehensive reviews [4-8] and references therein covering the state-of-the-art and highlighting the existing challenges within the area) [9]. Despite all challenges, it is safe to state that the basic principles of creating bioresorbable magnesium materials with the necessary combination of functional properties have been formulated, and a wide variety of biocompatible and bioresorbable alloying systems have been proposed in the literature. Of many existing variants, the design strategy of lightly alloyed $\mathrm{Mg}-\mathrm{Zn}-\mathrm{Ca}$ proposed by Uggowitzer and co-authors in a series of publications [10-15] is to be mentioned as one of the most viable and effective concepts. Zinc has long been recognised as one of the most effective alloying elements in Mg-based alloy compositions. With its relatively high maximum solubility in magnesium (of $6.2 \mathrm{wt} . \%$ ), zinc is undeniably an important solution strengthening agent increasing the critical resolved shear stress (CRSS) for basal slip. However, its function in $\mathrm{Mg}$ alloys is much broader than just providing a strengthening effect. For example, zinc is beneficial in overcoming the harmful effect of Fe and Ni impurities, thus increasing the overall corrosion resistance $[16,17]$. Calcium is the main component of human bone. It can strengthen the $\mathrm{Mg}$ matrix by combining solution strengthening, grain boundary strengthening and precipitation strengthening, though only moderately. Due to its low density $\left(1.55 \mathrm{~g} / \mathrm{cm}^{3}\right)$, $\mathrm{Ca}$ imbues the $\mathrm{Mg}$-Ca alloy system with the advantage of having a similar density to the bone. However, the prime function of $\mathrm{Ca}$ in the tertiary $\mathrm{Mg}-\mathrm{Zn}-\mathrm{Ca}$ systems lies in the formation of the specific intermetallic compounds affecting virtually all physical and (bio) chemical properties of the alloys [12-15]. Furthermore, the alloys with high Zn content suffer from rapid biocorrosion due to the abundant presence of the intermetallic phase $\mathrm{Mg}_{6} \mathrm{Zn}_{3} \mathrm{Ca}_{2}$. With the $\mathrm{Zn}$ content reduced to $1 \mathrm{wt}$.\% or less, the $(\mathrm{Mg}, \mathrm{Zn})_{2} \mathrm{Ca}$ phase prevails over $\mathrm{Mg}_{6} \mathrm{Zn}_{3} \mathrm{Ca}_{2}$. As it is less noble than the Mg-matrix, this phase does not act as a cathodic site, in contrast to $\mathrm{Mg}_{6} \mathrm{Zn}_{3} \mathrm{Ca}_{2}$. Homogeneously distributed Ca-containing precipitates influence dynamic recrystallisation and grain growth during hot processing, leading to the favourable formation of uniform microstructures. Finally, lean alloys with an attractive combination of high strength, ductility and superior bio-corrosion resistance have been produced, taking advantage of the combined effect of solid-solution hardening, grain-boundary hardening, and precipitation hardening [15].

Deformation processing is an essential component of the fabrication of any wrought alloy. However, it becomes of particular significance for the low-alloyed compositions, e.g., when the small concentration of $\mathrm{Zn}$ (of $1 \mathrm{wt} . \%)$ and $\mathrm{Ca}(<0.3 \%)$ is used to achieve the highest corrosion resistance. While conventional direct extrusion is by far the most popular process employed for the fabrication of $\mathrm{Mg}$ alloys, the unbeatable combination of high mechanical performance and corrosion resistance can be achieved by using a variety of severe plastic deformation (SPD) techniques [18], which are readily available for practitioners. These techniques have been used in different combinations to achieve extreme microstructure refinement, form a favourable crystallographic texture and homogenise the distribution of second phase particles contributing to the strength and controlling the overall corrosion resistance [19-22].

The development of perspective alloys is just the first task in the long chain of manufacturing operations, including a comprehensive characterisation of the microstructure and properties as necessary steps before the final medical devices can be produced and brought to market. Depending on the application, the implanting structures vary broadly in shapes and dimensions, which can often be as small as a few millimetres or sub-millimetres in one or two directions (e.g., wires, tubes, foils, scaffolds, etc.). The fabrication of products with such small dimensions involves metal forming through drawing, rolling or other processes to giant strains, assuming significant workability of the alloy. The ductility- 
permitting plastic deformation to large strains is often achieved at particular (usually narrow) temperature-strain rate regimes, which are not known a priory and need to be determined experimentally. Even though the significance of dynamic recrystallisation (DRX) has long been recognised for the mechanical behaviour and microstructure formation in $\mathrm{Mg}$ alloys at elevated temperatures [23-25], until recently, the number of reports documenting the mechanical response of perspective magnesium alloys in a wide temperature-strain rate range is still scarce. For example, some specific SPD schemes have been explored to find the optimised processing conditions [26,27]. Several recently emerged papers where the temperature-strain rate behaviour of magnesium alloys has been studied in considerable detail are to be mentioned. Ding et al. [28] established the optimal parameters of hot work deformation of the extruded AZ31 magnesium alloy in uniaxial compression in the temperature range of 250 to $500{ }^{\circ} \mathrm{C}$ at strain rates of $0.005-5 \mathrm{~s}^{-1}$. Backed by microstructural observations, the following guiding regimes have been formulated for the processing of AZ31: the temperature range is 300 to $400{ }^{\circ} \mathrm{C}$, and the strain rate range is 0.005 to $0.05 \mathrm{~s}^{-1}$. Zhang et al. [29] studied the thermomechanical behaviour of AZ31B and Elektron 717 $\mathrm{Mg}-\mathrm{Zn}$-Re-Zr alloys under hot forging conditions. These authors showed that dynamic recrystallisation accompanied by notable texture evolution occurred during deformation at a high homologous temperature in both alloys. These two interrelated processes were identified as key factors influencing the viscoplastic behaviour where the yield stress of both studied alloys decreased with increasing temperature and decreasing strain rate, while the ductility of the samples increased concurrently.

Aliyari et al. [30] investigated the behaviour of the potentially biocompatible alloy Mg-0.35Y-2.17Nd-0.36Zr (in wt.\%), which was hot extruded and then tested in tension in the temperature range of 225 to $525^{\circ} \mathrm{C}$ and strain rates which varied between $3 \times 10^{-4}$ and $3 \times 10^{-2} \mathrm{~s}^{-1}$. The deformation mode altered from the predominant twinning to dislocation slip when the temperature increased above $325^{\circ} \mathrm{C}$. Kaviani et al. [31] investigated the effect of hot deformation parameters (temperature and deformation rate) on the mechanical and corrosion properties of the biocompatible $\mathrm{Mg}-4 \mathrm{Zn}-0.5 \mathrm{Ca}-0.75 \mathrm{Mn}$ alloy. They showed that an increase in the deformation temperature positively affects corrosion properties. Chaman-Ara et al. [32], using the extruded Mg-Zn alloy with Y additions, investigated its microstructure and mechanical properties during hot compression in the temperature range of 300 to $450{ }^{\circ} \mathrm{C}$ and strain rates of 0.001 to $1 \mathrm{~s}^{-1}$. The deformation maps were constructed with optimal deformation conditions highlighted for enhanced deformability. The addition of $Y$ reduced the stress for the onset of DRX. Axial compression testing was used in the above-cited papers. Although it was noted in [32] that the deformation mode (compression or tension) does not significantly affect the processing maps for hot deformation of the alloy AZ31, the same assertion cannot be immediately generalised and expanded to the entire class of $\mathrm{Mg}$ alloys due to a well-known strong asymmetry in their mechanical response in tension and compression [33].

The complexity of the deformation behaviour of magnesium alloys is associated with the low symmetry of the hcp lattice resulting in the plurality of active deformation mechanisms involved in different combinations at different deformation stages [34]. Dislocation slip $\langle a\rangle$ on the most densely packed basal plane (0001) in the most closely packed direction is the dominant deformation mode at low homologous temperatures [35,36]. However, basal slip provides only two independent slip systems, which are not enough to accommodate the imposed plastic strain homogeneously. Even when all basal and non-basal systems are activated, the maximum four independent slip systems are activated [37,38], which is still insufficient to accommodate arbitrary homogeneous deformation of a polycrystalline aggregate according to the Taylor principle, which requires at least five independent slip systems [39]. Hence, non-basal slip systems, i.e., pyramidal slip and/or mechanical twinning, which is possible in several independent variants, must be activated. All these mechanisms have different critical resolved shear stresses and respond differently to testing temperature and strain rate. The complexity of the multi-faceted behaviour and mutual interplay between different deformation modes is far from being understood. The picture 
becomes particularly complicated when dynamic recrystallisation comes onto the stage, modifying the distribution and shapes of grains, their crystallographic orientation and the deformation mechanisms involved.

Investigation of the relationship between the microstructure resultant from the thermomechanical processing of an Mg-alloy and the deformation mechanisms occurring together with dynamic recovery and dynamic recrystallisation is a laborious task. To generate a comprehensive picture, one needs to obtain a large array of microscopic data with many combinations of test parameters: loading rate, temperature, imposed strain, etc. This work can be significantly facilitated if the microscopic studies are carried out in a guided way, that is, when critical conditions corresponding to the onsets of qualitative changes in deformation processes or the microstructure are indicated through independent in situ measurements. In order to determine such breakpoints, the method of acoustic emission (AE) is well suited since this AE phenomenon is intimately related to the local dynamic stress relaxation processes occurring during microstructural rearrangements in the material [40-42]. In the present work, we employ this method (for the first time, to the best of our knowledge) to investigate the deformation behaviour of the Mg-Zn-Ca alloy at elevated temperatures in situ.

\section{Materials and Methods}

\subsection{Alloy Processing}

A popular Mg-Zn-Ca alloying system [13,43,44] was chosen for the present study. After appropriate thermomechanical treatment, alloys of this kind have an excellent balance between mechanical and corrosion properties [45-49]. The alloy was cast from commercially pure components, and the chemical composition of the alloy-Mg- $0.85 \mathrm{Zn}-0.15 \mathrm{Ca}-0.012$ $\mathrm{Zr}$ (all in wt.\%) was determined by the optical emission spectrometer ARL 4460 OES (ThermoFisher Scientific, Waltham, MA, USA). Zirconium was added to the melt to reduce the content of iron to be below the tolerance limit [50,51]. In addition, $\mathrm{Zr}$ is known as an efficient grain refining agent. The amount of all trace elements did not exceed $0.1 \mathrm{wt} . \%$.

The as-cast alloy was homogenised at $430{ }^{\circ} \mathrm{C}$ for $12 \mathrm{~h}$ in argon. The billets of $150 \mathrm{~mm}$ length and $170 \mathrm{~mm}$ diameter were subjected to multiaxial isothermal forging (MIF) to 20 cycles with the total equivalent strain per cycle of 1.4 [52,53]. Each cycle comprised four forming operations, illustrated in Figure 1. The billet was preheated to $425^{\circ} \mathrm{C}$ and the first four MIF cycles were carried out at this temperature. The following cycles were performed with a $25^{\circ} \mathrm{C}$ temperature reduction after every four cycles with the final cycles carried out at $325^{\circ} \mathrm{C}$ [54]; finally, the billet was upset at $325^{\circ} \mathrm{C}$ and cut into plates.
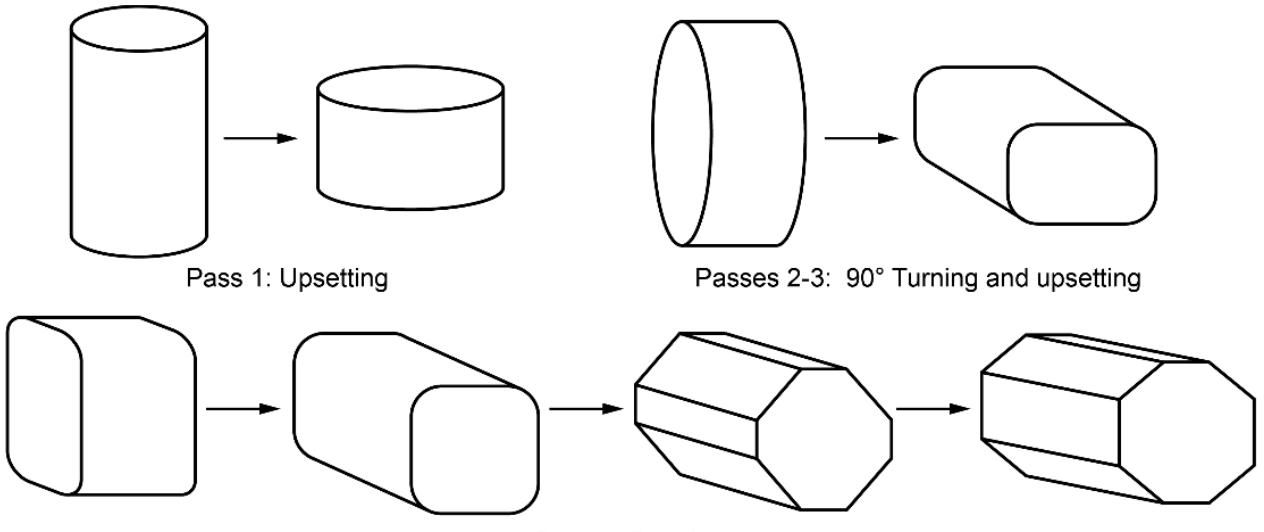

Pass 4: Drawing

Figure 1. Schematics of the multi-axial forging cycle.

\subsection{Mechanical Testing}

The standard tensile threaded I-shaped specimens with a round cross-section (as per recommendations of the ASTM E8/E8M-21 standard) were machined from the plates, as 
shown in Figure 2. The longitudinal axis of the specimens corresponded to the direction of the last upset operation (denoted as RD in analogy with the rolling direction). A flat facet of $16 \mathrm{~mm}$ length was machined on the shoulder part of the specimen to mount the AE sensor in proximity to the gauge part.

(a)

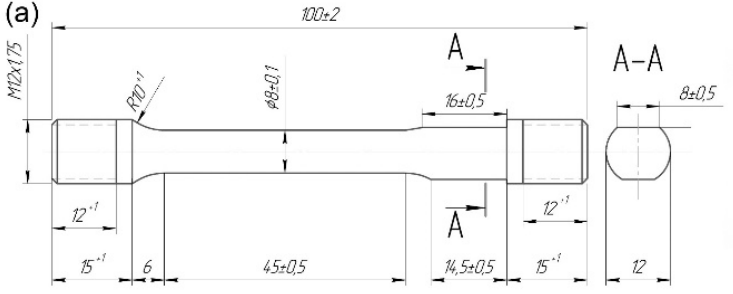

(b)

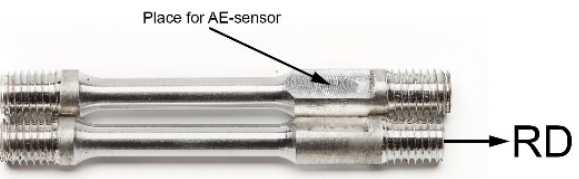

Figure 2. Schematic drawing (a) and photographic images (b) of the samples.

The experimental setup is shown in Figure 3 with key components are numbered and described in the caption. The specimens (1) for the uniaxial tensile tests were mounted in the heat-resistant grips (2) on a PC-controlled servohydraulic universal tensile machine Instron 8802 (Instron, Norwood, MA, USA) (5) equipped with an environmental chamber Instron 3119-406 (Instron, Norwood, MA, USA) (6) and BlueHill 3.0 software (Instron, Norwood, MA, USA). The strain was measured by a clip-on high-temperature extensometer Epsilon 3448 (Epsilon, Jackson, MO, USA) (3). Tests were performed under a crosshead velocity-controlled mode at nominal strain rates of $5 \times 10^{-4}, 5 \times 10^{-3}$ and $2 \times 10^{-2} \mathrm{~s}^{-1}$, and temperatures $20,100,150,200$ and $250{ }^{\circ} \mathrm{C}$. One specimen was tested at $100{ }^{\circ} \mathrm{C}$ at $2 \times 10^{-2} \mathrm{~s}^{-1}$ to confirm the general trends. Two thermocouples (7) were attached to both sides of the specimen to ensure temperature stability to be better than $\pm 2{ }^{\circ} \mathrm{C}$.

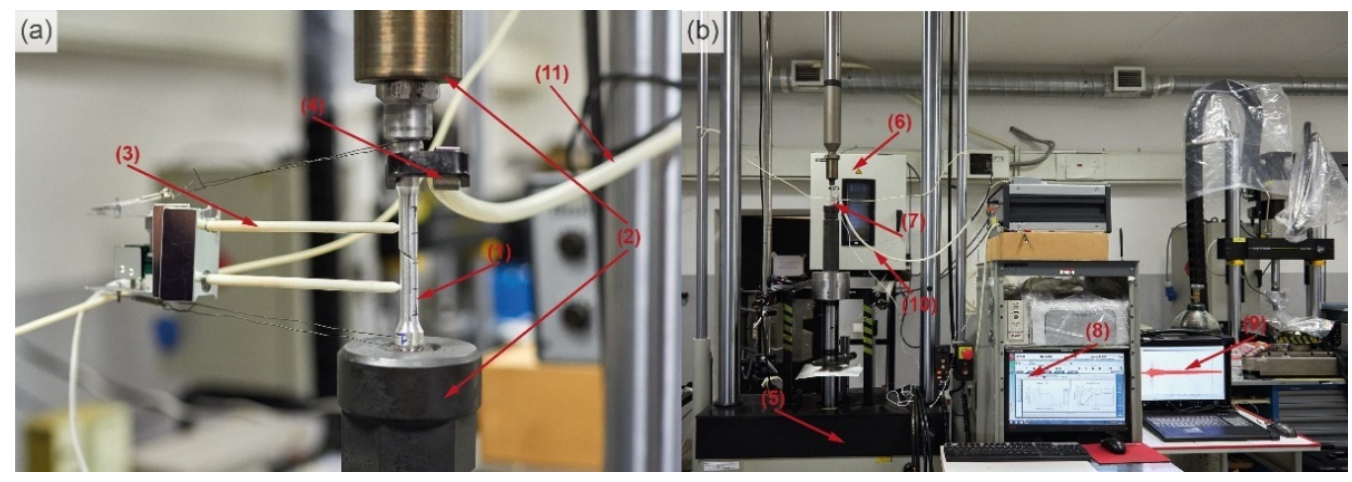

Figure 3. Experimental setup: (a) magnified view of the specimen and (b) general view of the testing facilities; (1)—specimen; (2)—high-temperature grips; (3)—extensometer with ceramics probes; (4)— AE sensor; (5)—Instron 8802 servohydraulic frame; (6)—environmental chamber; (7)—thermocouple; (8)—test-controlling PC; (9)—AE system; (10)—AE sensor clamp; (11)—air-chilled thermal insulating shell for the AE signal cable.

\subsection{Acoustic Emission Method}

For AE measurements, the piezoelectric sensor MSEA-1300WB (Microsensors AE, Sarov, Russia), Figure 3a(4), calibrated as described in [55], was attached to the shoulder part of the specimen (1) with the elastic clamp (10). Vacuum oil was used as a coupling medium to ensure the efficient transfer of elastic waves from the surface to the transducer. The AE signals were amplified by $60 \mathrm{~dB}$ in the frequency band from 10 to $1200 \mathrm{kHz}$ by the low-noise pre-amplifier 2/4/6 and recorded by the 16-bit PCI-2 data acquisition board (MISTRAS, Princeton, NJ, USA), Figure 3b(9), operating in the "thresholdless" mode at the sampling rate of 2 Msamples/s in the frequency band of 100-1000 kHz. An additional $+6 \mathrm{~dB}$ gain was set on board. The AE measurements at elevated temperatures are challenging as virtually all commercially available so-called high-temperature sensors have a 
significantly compromised sensitivity and/or bandwidth. The LiNb-based piezoelectric element utilised in the sensor MSAE-1300WB with a frequency band of $50-1300 \mathrm{kHz}$ is featured by its high Curie temperature and sensitivity comparable to that of most commercial PZT transducers [55]. Furthermore, the coaxial cable has a thermal insulating shell, which was air-cooled during testing, Figure $3 a(11)$. The cable temperature was measured by a thermocouple attached to the hot side of the shall. The pressure and the rate of the cooling air were kept constant during the test.

The continuously streamed data were sectioned into consecutive individual realisations of $4 \mathrm{k}$ samples without overlapping. A Fourier power spectral density (PSD) function $G(f)$ was then calculated from these data using a Welch method. The average per realisation $A E$ energy $E$ was calculated from the corresponding PSD as $E_{A E}=T \int_{f_{\min }}^{f_{\max }} G(f) d f(T$ is the length of the realisation). The median AE frequency $f_{m}$ was introduced according to the definition $\int_{0}^{f_{m}} G(f) d f=\int_{f_{m}}^{\infty} G(f) d f$, see [56] for details. Both $E$ and $f_{m}$ values were obtained from $G(f)$ after subtraction of the PSD of the laboratory noise pre-recorded before the start of loading during each test.

\subsection{Microstructure Characterisation}

The X-ray diffraction (XRD) technique was employed for the phase analysis using the Shimadzu Maxima XRD-7000 (Shimadzu, Kyoto, Japan) diffractometer with a goniometer in the Bragg-Brentano geometry with a secondary curved graphite monochromator (long focus tube with $\mathrm{CuK} \alpha$ radiation, $40 \mathrm{~mA}$ current and $40 \mathrm{kV}$ accelerating voltage, respectively). Scanning was carried out over the $10-90^{\circ} 2 \theta$ range at $0.5 \mathrm{deg} / \mathrm{min}$ scan speed with 0.02 deg steps. The phases were identified using the Shimadzu PDF2 database.

The sections for the EBSD analysis were cut from the middle of the gauge part of the tensile specimens normally to the longitudinal axis (RD in Figure 2). All sections were gently mechanically ground by $\mathrm{SiC}$ paper down to \#2500-grade and then further polished with diamond pastes down to $0.25 \mu \mathrm{m}$ particle size to a mirror-like finish. Finally, the surface of the sections was ion milled by a Hitachi IM4000 Plus system (Hitachi, Tokyo, Japan) using a low-energy Ar+ ion beam. The optimum milling conditions were found with the $3^{\circ}$ inclination angle to the surface, $6 \mathrm{kV}$ acceleration voltage and $1.5 \mathrm{kV}$ discharge voltage, $0.1 \mathrm{~cm}^{3} \mathrm{~min}^{-1}$ argon gas flow and $25 \mathrm{rpm}$ for $1-2 \mathrm{~h}$ milling time.

The microstructure in the initial state after straining at elevated temperature was investigated by the field emission gun scanning electron microscope (SEM) SIGMA (Zeiss, Jena, Germany) equipped with the Hikari electron backscattering diffraction (EBSD) camera (EDAX/TSL, Mahwah, NJ, USA) and orientation image microscopy software package OIM-6.2 from the same company. The EBSD maps were obtained from the regions of $160 \times 160 \mu \mathrm{m}^{2}$ with a step size of $250-350 \mathrm{~nm}$. The indexed points with a confidence index less than 0.1 were ignored in post-processing. The grains were identified using a minimum misorientation angle of $5^{\circ}$, and the grain diameter was determined from the grain area, assuming a spherical grain. The grain boundaries were defined by means of misorientation between the adjacent points, with boundaries having a misorientation between $2^{\circ}-15^{\circ}$ regarded as low angle grain boundaries (LAGBs) and boundaries with a misorientation larger than $15^{\circ}$ evaluated as high angle grain boundaries (HAGBs). For the grain identification procedure, the criterion for reliability was used with not less than 6-8 points with co-directional orientation within 5 degrees of misorientation [57].

\section{Results}

The result of the XRD scan shown in Figure 4 revealed distinct peaks corresponding to $\alpha-\mathrm{Mg}$. The reflexes of $\mathrm{CaO}$ oxide and the $\mathrm{CaZn}_{13}$ phase were found in the XRD pattern. However, in good agreement with thermodynamic predictions [15], there was no sign of the tertiary intermetallic compounds, such as $\mathrm{Ca}_{2} \mathrm{Mg}_{6} \mathrm{Zn}_{3}$ phase or $\mathrm{Ca}_{2} \mathrm{Mg}_{5} \mathrm{Zn}_{3}$, Figure $4 \mathrm{~b}$, which are commonly seen in many $\mathrm{Mg}-\mathrm{Zn}-\mathrm{Ca}$ alloys with a higher content of $\mathrm{Zn}$ and $\mathrm{Ca}[48,58,59]$. However, traces of a small amount of the $\mathrm{Mg}_{2} \mathrm{Ca}$ phase and undissolved 
Ca particles were found in the diffractograms, which were particularly well visible on the diffraction pattern obtained with a higher resolution, Figure $4 \mathrm{~b}$.
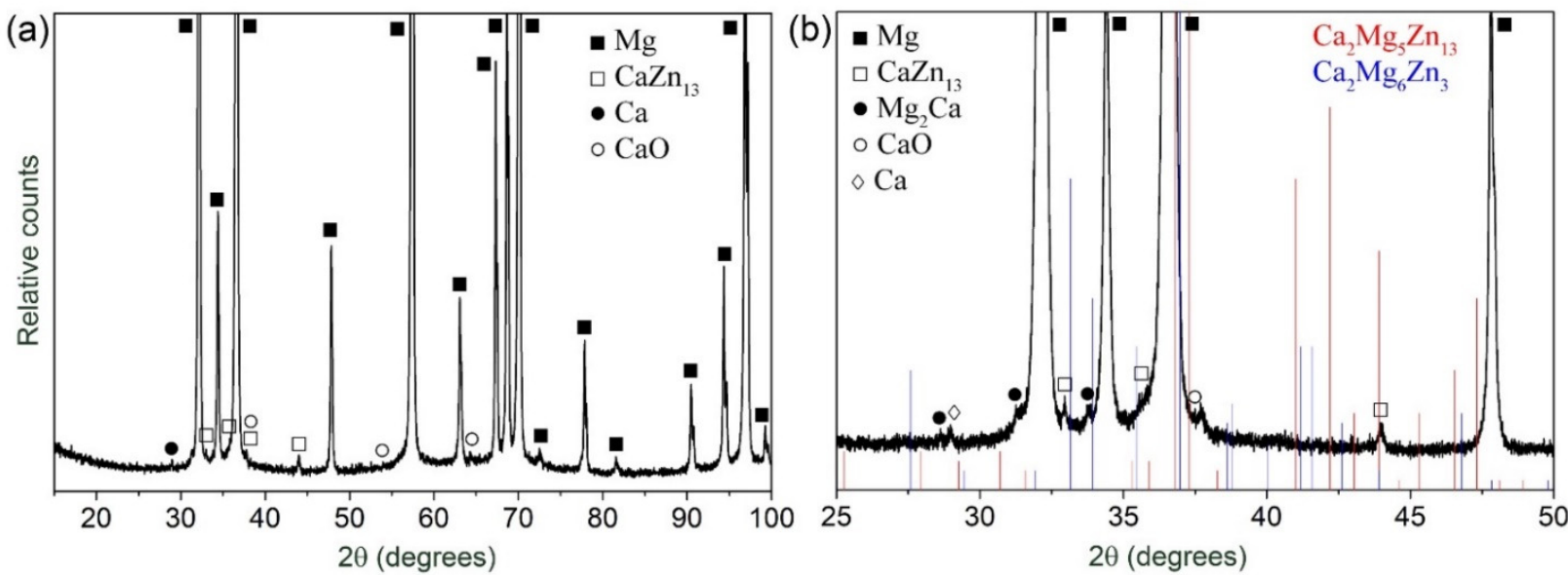

Figure 4. The X-ray diffraction pattern of the as-fabricated Mg-1Zn-0.2Ca alloy: (a) full scan, (b) fragment of the XRD pattern obtained at a slower scan speed of $0.1 \mathrm{deg} / \mathrm{min}$ with a scan step of $0.005 \mathrm{deg}$.

The initial microstructure was characterised by a wide distribution of grain shapes and dimensions, Figure 5a. Although the grains size distribution was unimodal, the effective grain diameters varied from 1 to $25-30 \mu \mathrm{m}$, Figure $5 \mathrm{~b}$. The maximum of the histogram lies in the fine grain domain corresponding to grain sizes of 2-3 $\mu \mathrm{m}$. The misorientation angles were distributed nearly evenly, with the broad peak around $30^{\circ}$. This microstructure indicated that the recrystallisation process during isothermal forging operations had not been completed. The large grains appeared elongated in the plane of the last upsetting (horizontal direction in Figure 5c).
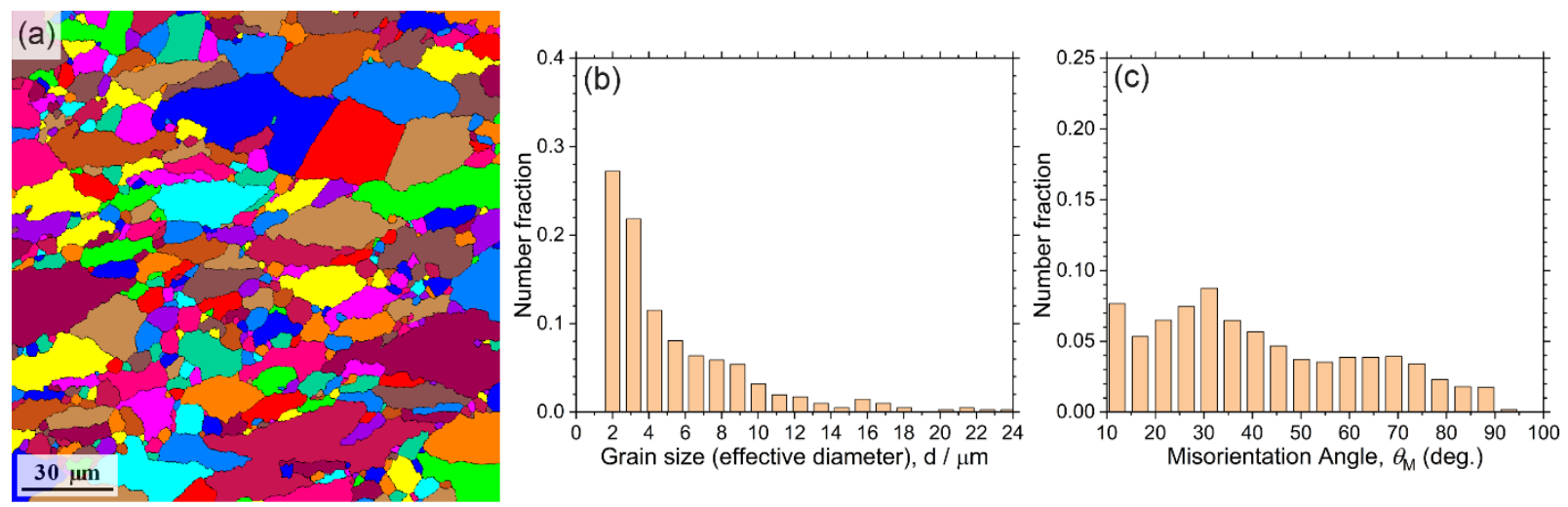

Figure 5. Initial microstructure of the $\mathrm{Mg}-1 \mathrm{Zn}-0.2 \mathrm{Ca}$ alloy (a) and its parameters: (b) - grain size distribution; (c) - distribution of the angles of misorientation between grains.

\subsection{Mechanical Behaviour at Ambient and Elevated Temperatures}

Engineering stress-strain diagrams for uniaxial tension at various temperatures and strain rates are summarised in Figure $6 \mathrm{a}-\mathrm{e}$. The conventional yield stress $\sigma_{0.2}$, ultimate tensile strength $\sigma_{U T S}$, elongation at break $\varepsilon_{f}$ and the average strain-hardening rate $\theta_{3-10}$ determined between $3 \%$ and $10 \%$ strain are represented in Table 1 . To ease the observation of changes in the tensile diagrams with temperature, Figure $6 f$ shows the $\sigma(\varepsilon)$ curves obtained at the same strain rate of $5 \times 10^{-3} \mathrm{~s}^{-1}$ and different temperatures. As expected, the tensile strength decreased, while the elongation to failure increased with increasing temperature. Most notable changes in the mechanical response were observed starting 
from $250{ }^{\circ} \mathrm{C}$. The interesting result is that the yield stress increased at $150{ }^{\circ} \mathrm{C}$ compared to that at ambient temperature and then decreased with increasing test temperature. This anomaly in the behaviour of the yield stress has yet to be understood on the basis of detailed microstructural examinations, which are beyond the scope of the present work, and which will be the focus of our further investigations.
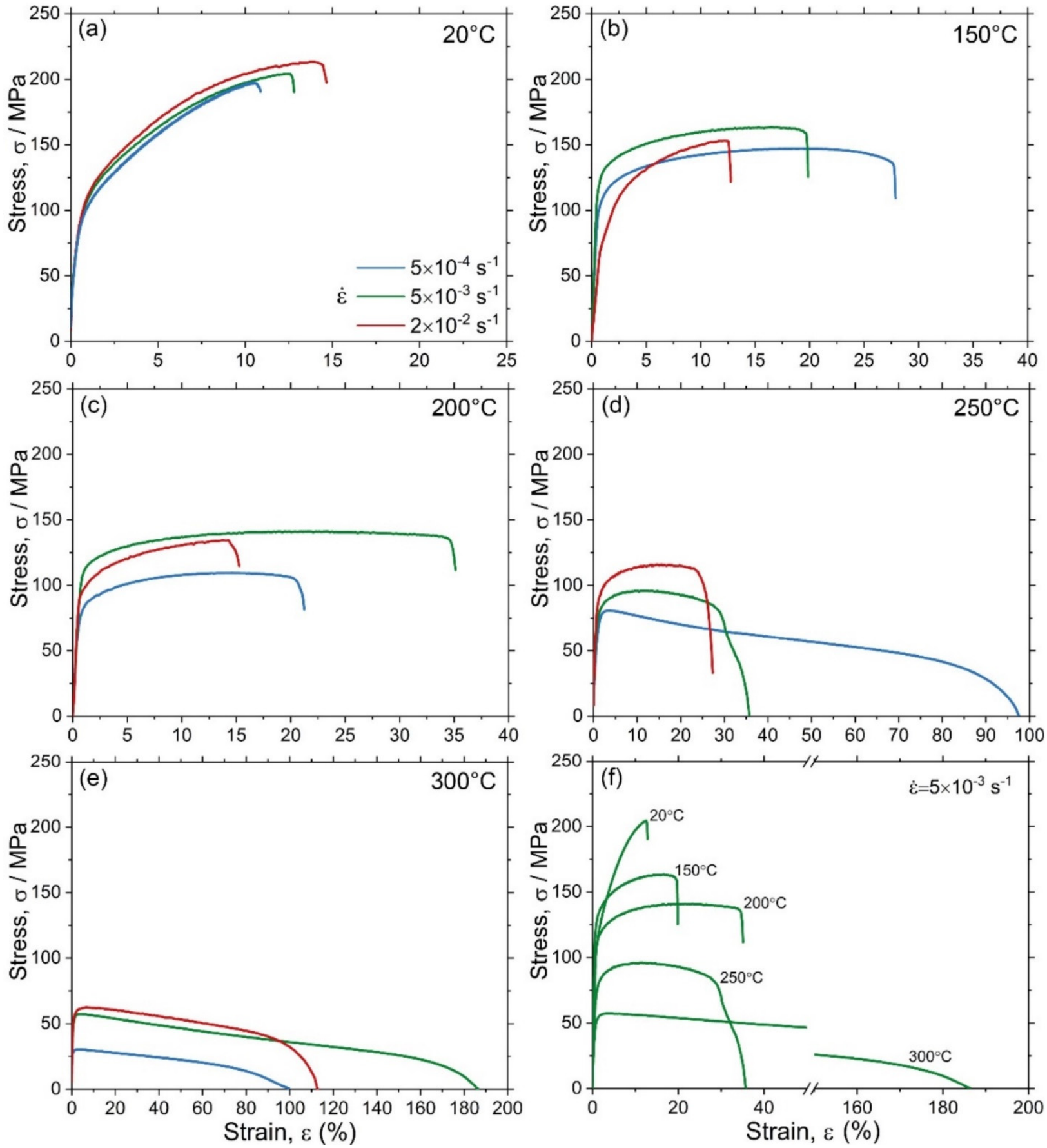

Figure 6. Tensile diagrams for the specimens tested at various temperatures and three strain rates (the colour coded legend shown in (a) applies to all plots): (a) $20{ }^{\circ} \mathrm{C},(\mathbf{b}) 150{ }^{\circ} \mathrm{C},(\mathbf{c}) 200{ }^{\circ} \mathrm{C}$, (d) $250{ }^{\circ} \mathrm{C}$, (e) $300^{\circ} \mathrm{C}$, and (f) the summary plot showing the evolution of the $\sigma(\varepsilon)$ curves obtained at $\dot{\varepsilon}=5 \times 10^{-3} \mathrm{~s}^{-1}$ with increasing test temperature. 
Table 1. Mechanical properties and acoustic emission parameters.

\begin{tabular}{|c|c|c|c|c|c|c|c|c|}
\hline $\mathrm{T},{ }^{\circ} \mathrm{C}$ & $\dot{\varepsilon}, s^{-1}$ & $\sigma_{0.2}, \mathrm{MPa}$ & $\sigma_{\text {UTS }}, \mathbf{M P a}$ & $\varepsilon_{f}, \%$ & $\theta_{3-10}, \mathrm{MPa}$ & $\sigma_{0}^{A E}, \mathbf{M P a}$ & $\sigma_{\max }^{A E}, \mathrm{MPa}$ & $\varepsilon_{c r}^{A E}, \%$ \\
\hline \multirow{3}{*}{20} & $5 \times 10^{-4}$ & $74 \pm 2.5$ & $193 \pm 3$ & $10.5 \pm 0.5$ & $734 \pm 24$ & $60 \pm 4$ & $93 \pm 4$ & $>\varepsilon_{f}$ \\
\hline & $5 \times 10^{-3}$ & $77 \pm 3$ & $200 \pm 3$ & $12.5 \pm 1$ & $793 \pm 29$ & $23 \pm 1$ & $82 \pm 3$ & $>\varepsilon_{f}$ \\
\hline & $2 \times 10^{-2}$ & $77 \pm 3$ & $210 \pm 3$ & $14 \pm 1$ & $835 \pm 32$ & $38 \pm 2$ & $74 \pm 3$ & $>\varepsilon_{f}$ \\
\hline 100 & $2 \times 10^{-2}$ & 76 & 167 & 16 & 563 & 38 & 78 & $>\varepsilon_{f}$ \\
\hline \multirow{3}{*}{150} & $5 \times 10^{-4}$ & $100 \pm 4$ & $141 \pm 3$ & $28 \pm 2$ & $222 \pm 9$ & $45 \pm 2$ & $82 \pm 3$ & $4.8 \pm 0.2$ \\
\hline & $5 \times 10^{-3}$ & $120 \pm 5$ & $162 \pm 5$ & $20 \pm 2$ & $224 \pm 11$ & $45 \pm 2$ & $73 \pm 3$ & $7 \pm 0.3$ \\
\hline & $2 \times 10^{-2}$ & $62 \pm 2.5$ & $148 \pm 3$ & $13 \pm 1$ & $490 \pm 18$ & $30 \pm 2$ & $58 \pm 2$ & $>\varepsilon_{f}$ \\
\hline \multirow{3}{*}{200} & $5 \times 10^{-4}$ & $75 \pm 3$ & $108 \pm 3$ & $22 \pm 2$ & $178 \pm 9$ & $26 \pm 3$ & $72 \pm 3$ & $2.5 \pm 0.1$ \\
\hline & $5 \times 10^{-3}$ & $105 \pm 4$ & $140 \pm 5$ & $36 \pm 5$ & $182 \pm 9$ & $28 \pm 3$ & $68 \pm 3$ & $5.0 \pm 0.2$ \\
\hline & $2 \times 10^{-2}$ & $102 \pm 4$ & $135 \pm 6$ & $15 \pm 1$ & $237 \pm 11$ & $63 \pm 4$ & $80 \pm 3$ & $12 \pm 0.4$ \\
\hline \multirow{3}{*}{250} & $5 \times 10^{-4}$ & $56 \pm 2$ & $80 \pm 3$ & $96 \pm 12$ & $-58 \pm 8$ & - & - & - \\
\hline & $5 \times 10^{-3}$ & $65 \pm 3$ & $96 \pm 3$ & $30 \pm 2$ & $58 \pm 7$ & $35 \pm 2$ & $64 \pm 3$ & $1.7 \pm 0.1$ \\
\hline & $2 \times 10^{-2}$ & $70 \pm 3$ & $115 \pm 5$ & $25 \pm 2$ & $165 \pm 10$ & $23 \pm 2$ & $58 \pm 3$ & $2.8 \pm 0.1$ \\
\hline \multirow{3}{*}{300} & $5 \times 10^{-4}$ & $22 \pm 2$ & $30 \pm 3$ & $120 \pm 30$ & $-39 \pm 20$ & - & - & - \\
\hline & $5 \times 10^{-3}$ & $44 \pm 3$ & $57 \pm 4$ & $180 \pm 35$ & $-16 \pm 8$ & - & - & - \\
\hline & $2 \times 10^{-2}$ & $51 \pm 3$ & $63 \pm 4$ & $110 \pm 20$ & $19 \pm 8$ & - & - & - \\
\hline
\end{tabular}

\subsection{Acoustic Emission}

Figure 7 shows the typical behaviour of the AE spectral characteristics represented by the energy and median frequency in dependence on time (or strain) synchronised with the respective $\sigma(\varepsilon)$ diagrams. To get a better understanding of the effects of temperature and strain rate on $\mathrm{AE}$, Figure $7 \mathrm{a}-\mathrm{e}$ compare the results obtained for the same strain rate of $2 \times 10^{-2} \mathrm{~s}^{-1}$, but different temperatures. Moreover, Figure $7 \mathrm{~d}, \mathrm{f}, \mathrm{g}$ illustrate the data obtained with the strain rates varying at the same test temperature of $200{ }^{\circ} \mathrm{C}$. For the tests performed at $250^{\circ} \mathrm{C}$ at the lowest strain rate (as well as for all tests performed at $300{ }^{\circ} \mathrm{C}$ ), the $\mathrm{AE}$ level was quite low, i.e., close to the background noise. Therefore, these results were excluded from the analysis in the present work.

Typically, for most metallic materials [60], during loading of the alloy Mg-1Zn-0.2Ca, the AE energy peaked shortly after the onset of plastic yielding and decayed gradually afterwards in response to the growing dislocation density and a concomitant decrease in the dislocation mean free path. Concurrently, the AE spectrum shifted to a higher frequency domain, as was reflected by the steady increase in the median frequency with strain up to the onset of necking instability. Figure 8a illustrates the formation of the AE peak as a function of the flow stress $\sigma$. A test carried out at $200{ }^{\circ} \mathrm{C}$ and $5 \times 10^{-3} \mathrm{~s}^{-1}$ strain rate was used as a representative example. One can see that the $\mathrm{AE}$ peak has a nearly symmetrical bell shape in the $E-\sigma$ coordinates. Two characteristic AE features are worthy of notice: the stress corresponding to the first departure of the $\mathrm{AE}$ signal from the noise level $\sigma_{0}^{A E}$, and the stress corresponding to the AE maximum $\sigma_{\max }^{A E}$. Ideally, these two quantities define the lowest detectable stress when plastic deformation activates in local volumes of the material (notably, far below the conventional yield stress), and the stress when the entire undeformed volume becomes involved in plastic yielding. Commencing locally in individual grains, which were most suitably oriented for dislocation initiation or contain residual stress concentrators, plastic flow expanded to the entire volume with increasing stress. These two specifically determined stresses can be referred to as the AE elastic limit and the AE yield stress, respectively. 

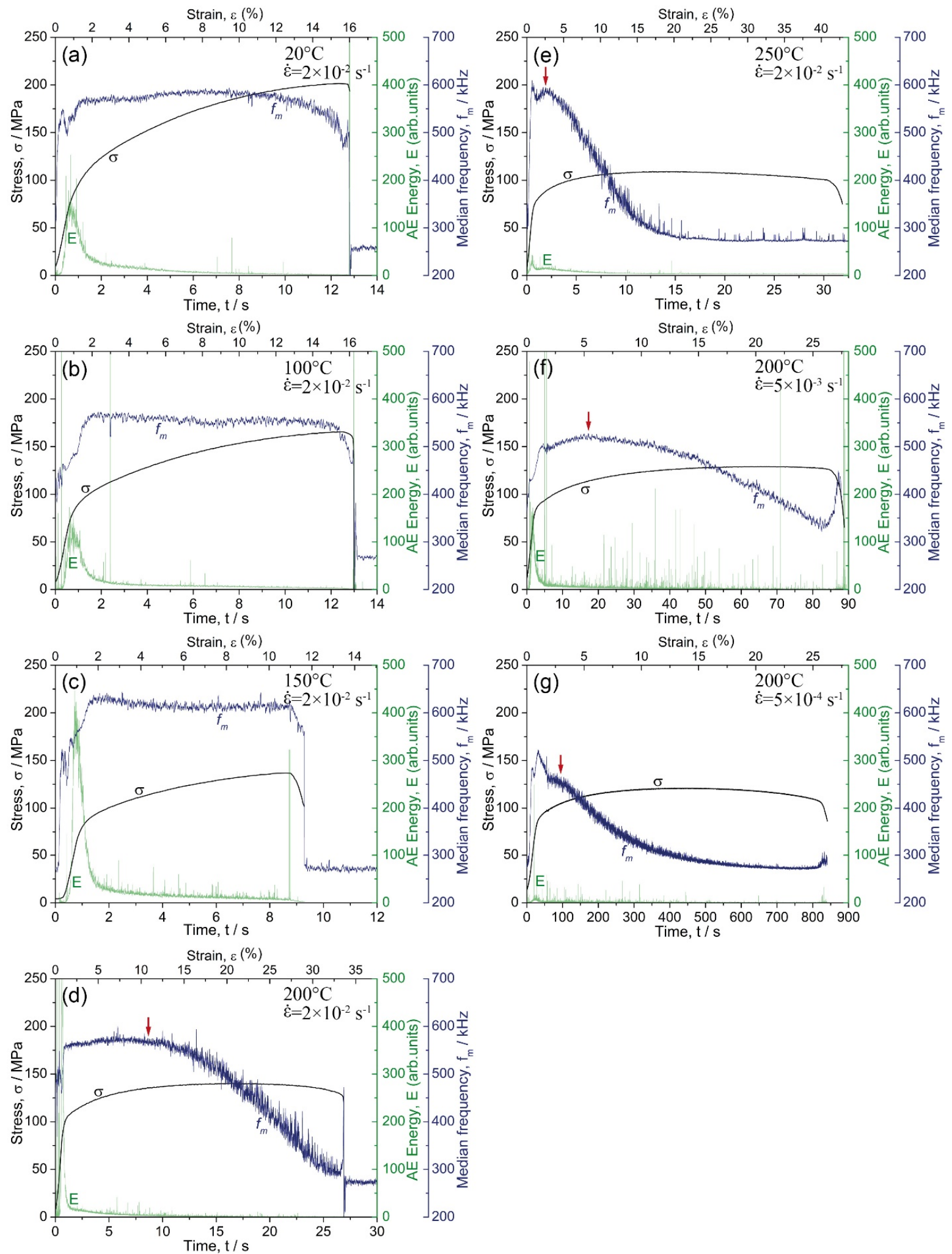

Figure 7. The AE energy and median frequency behaviour as a function of deformation time (strain) in tension at $2 \times 10^{-2} \mathrm{~s}^{-1}$ strain rate and testing temperatures $20(\mathbf{a}), 100(\mathbf{b}), 150$ (c), 200 (d) and $250{ }^{\circ} \mathrm{C}$ (e); plots (f) and (g) show the same parameters for testing at $200{ }^{\circ} \mathrm{C}$ and $\dot{\varepsilon}=5 \times 10^{-3} \mathrm{~s}^{-1}$ and $5 \times 10^{-4} \mathrm{~s}^{-1}$, respectively. Arrows in $(\mathbf{d}-\mathbf{g})$ indicate the breakpoints in the $f_{m}$ trends from ascending to descending at the strain $\varepsilon_{c r}^{A E}$. 

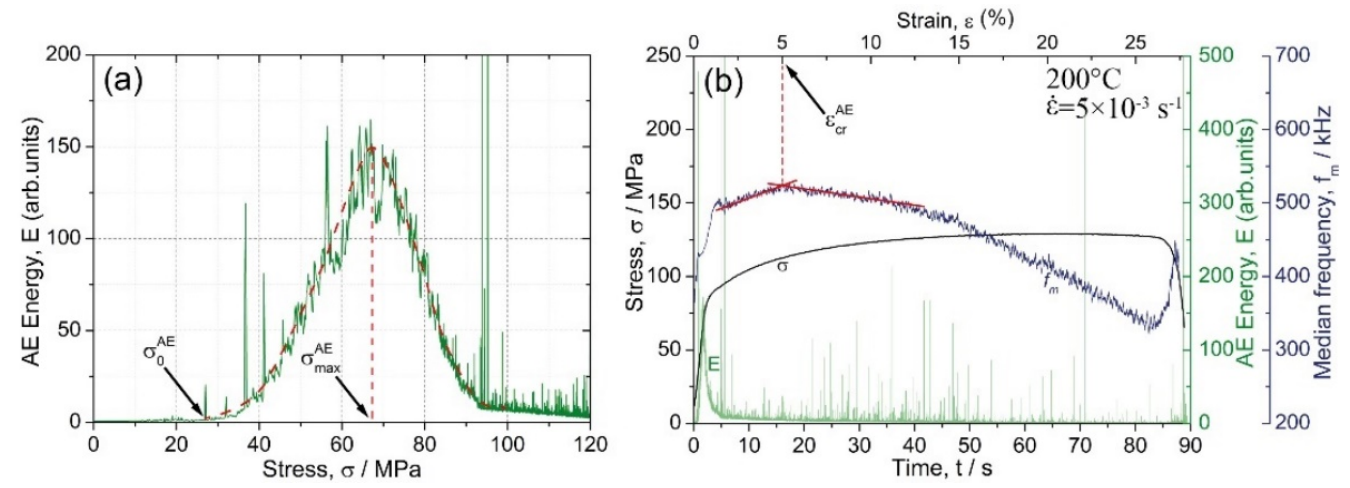

Figure 8. Schematic of determining the AE characteristics using the example of testing results obtained at $200{ }^{\circ} \mathrm{C}$ and $\dot{\varepsilon}=5 \times 10^{-3} \mathrm{~s}^{-1}$; (a) stress corresponding to the onset of AE $\sigma_{0}^{A E}$ (AE elastic limit), and stress corresponding to the $\mathrm{AE}$ peak $\sigma_{\max }^{A E}$ (AE yield stress); (b) critical strain $\varepsilon_{c r}^{A E}$ corresponding to the breakpoint in the $f_{m}$ behaviour.

As reflected by the AE median frequency, the AE spectral density exhibited a clear shift to a high-frequency domain in parallel with the flow stress as long as plastic deformation was mediated by dislocation slip during the uniform deformation stage [61-63]. This trend broke in three situations: (i) when the mechanisms other than dislocation slip came onto the stage, e.g., twinning [34,64,65], or martensitic transformation in TWIP and TRIP steels $[66,67]$ (it has been shown in the cited works that when profuse twinning is observed, the $f_{m}$ value tends to level out); (ii) when the strain localisation occurred, and the plastic flow was governed by substantially correlated dislocation motion [68], and (iii) if, for any reason, the dislocation mean free path increased as opposed to the strain hardening process. One can see that the AE median frequency behaved notably differently with straining at different testing temperatures. At ambient and relatively low temperatures of 100 and $150{ }^{\circ} \mathrm{C}$, the AE median frequency increased at the onset of plastic flow and tended to saturate with only a slight (or no) trend to decrease at the mature deformation stage (a similar finding has been reported formerly for the alloy ZK60 deformed at room temperature [61,62]). However, at a temperature equal to or higher than $200{ }^{\circ} \mathrm{C}$, the behaviour of the median frequency changed drastically from the steady flow to the rapid decrease after a certain critical strain $\varepsilon_{c r}^{A E}$, Figure $7 \mathrm{~d}$,e. Moreover, the appreciable decrease in $f_{m}$ commenced at lower strains as the strain rate decreased, Figure $7 \mathrm{~g}$,f. Figure $8 \mathrm{~b}$ illustrates the scheme of how $\varepsilon_{c r}^{A E}$ was determined. Values of $\sigma_{0}^{A E}, \sigma_{\max }^{A E}$ and $\varepsilon_{c r}^{A E}$ determined from AE measurements are shown in Table 1 together with the corresponding data derived from the stress-strain curves under different testing conditions.

\section{Discussion}

As has been mentioned, the alloy strength decreased with increasing test temperature while the ductility increased simultaneously. The change in these quantities appeared to be most pronounced at $250{ }^{\circ} \mathrm{C}$ and higher temperatures, Figure 9a. Trends were the opposite with an increasing strain rate: strength increased while ductility decreased, as is commonly seen for structural materials where deformation is mediated by thermally activated mechanisms, such as dislocation slip. The average strain hardening rate decreased nearly linearly with increasing temperature for all strain rates used in the tests, Figure $9 \mathrm{~b}$. However, the effect of strain rate was more pronounced at higher strain rates. 
(a)

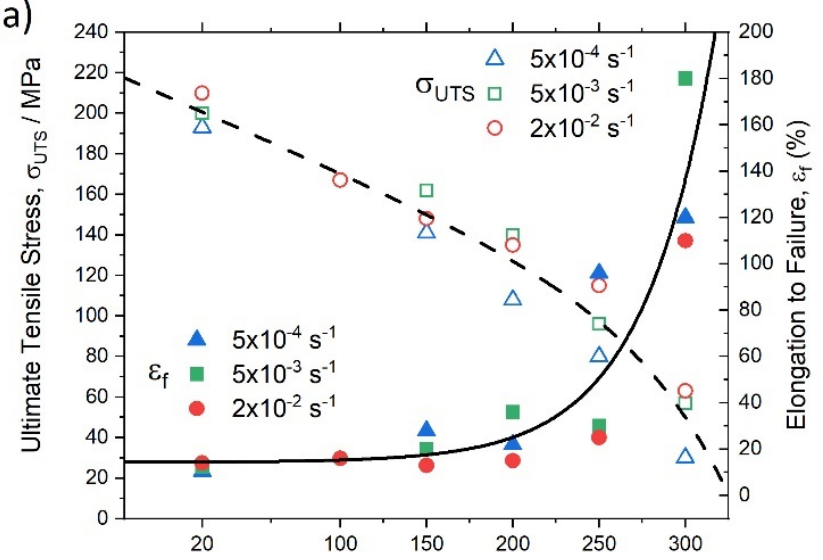

(c)

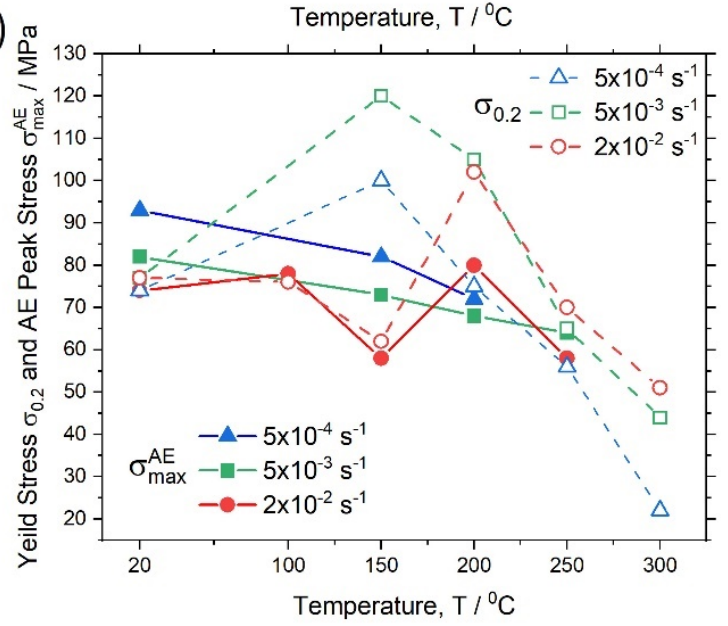

(b)

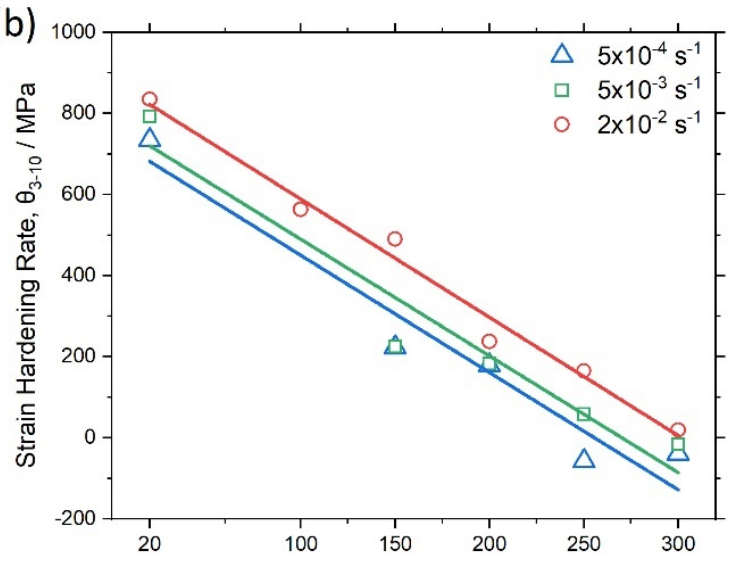

(d)

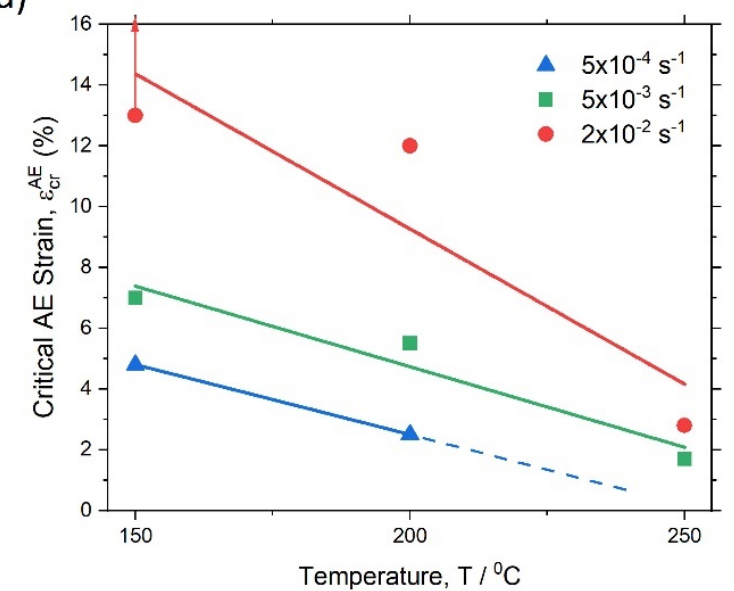

Figure 9. Dependence of mechanical properties and AE features on the test temperature: (a) ultimate tensile strength $\sigma_{U T S}$ and elongation at break $\varepsilon_{f},(\mathbf{b})$ average strain hardening rate $\theta_{3-10}$, (c) conventional yield stress $\sigma_{0.2}$ and $\mathrm{AE}$ (or physical) yield stress $\sigma_{\max }^{A E}$, and (d) critical strain $\varepsilon_{c r}^{A E}$.

While many mechanical properties exhibited stable trends with increasing test temperature $\left(\sigma_{U T S}, \varepsilon_{f}, \theta_{3-10}\right)$, the properties demonstrating the most irregular behaviour were those reflecting the elastic-plastic transition: the conventional yield stress $\sigma_{0.2}$ and the "physical" yield stress corresponding to the peak AE $\sigma_{\max }^{A E}$, Figure 9c. One can see that these characteristics behaved most irregularly at $150{ }^{\circ} \mathrm{C}$, i.e., their values sporadically and sharply varied for different strain rates. The stress corresponding to the appearance of a stably detectable AE signal (elastic limit related likely to the CRSS in the most favourably oriented grains) showed an even greater scatter. It is highly likely that this irregular behaviour of stress-related characteristics at the very early deformation stage is associated with the competition between two alternative deformation modes-basal slip and twinning [69-74] — having comparable yet slightly different CRSS depending on temperature and strain rate (admittedly, finding the CRSS values precisely in polycrystals is a difficult task [75]). While basal slip was the predominant deformation mechanism in $\mathrm{Mg}$, profuse twinning activated at low homologous temperatures, whereas a combination of basal and non-basal slip modes governed the plastic flow at high temperatures. One can suppose that the competition between sip and twinning becomes most fierce at $150{ }^{\circ} \mathrm{C}$ for a given alloy. Jain and Agnew [76] and Chapuis and Liu [77] showed that for the alloy AZ31, the CRSS value for $\{10 \overline{1} 2\}$ tension twinning increased with temperature, and $\{10 \overline{1} 1\}$ compression twinning did not show up above $150^{\circ} \mathrm{C}$. This finding, although it is promising and nicely illustrating the capacity of the modern $\mathrm{AE}$ technique to detect small scale plastic events at the very early deformation stage, and, thereby, to clarify the CRSS value for the corresponding mechanisms, addressing this issue is beyond the scope of the present work. 
Figure $9 \mathrm{~d}$ shows the dependence of the critical strain $\varepsilon_{c r}^{A E}$ (corresponding to the beginning of the decrease in $f_{m}$ ) on the test temperature (notice that at $150{ }^{\circ} \mathrm{C}$, such a point was not found; therefore, the elongation at break is shown in Figure $9 \mathrm{~d}$ for this temperature). As can be seen, the $\varepsilon_{c r}^{A E}$ value persistently decreased with an increase in temperature and/or decrease in strain rate. As has been discussed above, the AE median frequency is a spectral feature characterising the relaxation time in the 1st order stochastic autoregressive process of AE generation [61], which is governed by the inter-obstacle spacing, i.e., by the mean free path of dislocations. Therefore, as has been discussed above, the $f_{m}$ value tends to increase monotonically in response to the increase in the accumulated dislocation density as strain hardening proceeds. The present observations, however, showed the break in this common trend: starting from the critical strain $\varepsilon_{c r}^{A E}, f_{m}$ decreased, indicating unequivocally that the mean free path of dislocations increased. Perhaps, the only rational explanation for this behaviour would assume that partial recovery occurs in the microstructure as a result of dynamic recrystallisation. If this is the case, then the strain $\varepsilon_{c r}^{A E}$ could be related to the coarsening of recrystallised grains, which, in the just recrystallised state, were free from dislocations.

To verify this hypothesis, the following additional experiments were performed. For each of the three test temperatures $\left(150,200\right.$ and $\left.250{ }^{\circ} \mathrm{C}\right)$, three interrupted tensile tests were carried out. The tests were terminated when the following conditions on strains were met at the critical $\varepsilon_{c r}^{A E}$ for a given strain rate, as well as at the lower and higher strains denoted in Table 2 as $\left\langle\varepsilon_{c r}^{A E}\right.$ and $>\varepsilon_{c r}^{A E}$, respectively. After unloading, the sections were cut from the middle of the gauge part of the specimens as described in Section 3.1, and the microstructure was investigated by the EBSD technique.

Table 2. Values of strain attained in the tests interrupted according to $\varepsilon_{c r}^{A E}$.

\begin{tabular}{ccccc}
\hline \multirow{2}{*}{$\mathbf{T},{ }^{\circ} \mathbf{C}$} & Strain Rate, $\dot{\varepsilon}, \mathbf{s}^{-\mathbf{1}}$ & $<\varepsilon_{c r}^{A E}$ & $\begin{array}{c}\text { Strain (\%) } \\
\varepsilon_{c r}^{A E}\end{array}$ & $>\varepsilon_{c r}^{A E}$ \\
\hline 150 & $5 \times 10^{-3}$ & 4.0 & 7.0 & 15 \\
200 & $5 \times 10^{-3}$ & 3.0 & 5.0 & 10 \\
250 & $2 \times 10^{-4}$ & 1.5 & 2.8 & 8.0 \\
\hline
\end{tabular}

The prime results of the investigation of the microstructure for the specimens tested at $200{ }^{\circ} \mathrm{C}$ and $\dot{\varepsilon}=5 \times 10^{-3} \mathrm{~s}^{-1}$ are shown in Figures 10 and 11 At the strain stop of $3 \%$ $\left(<\varepsilon_{c r}^{A E}\right)$, the microstructure consisted of strongly deformed grains, Figure 10a. Compared to the initial state, Figures $5 b$ and $11 a-c$, one can notice a greatly increased fraction of fine grains, Figures $10 \mathrm{~b}$ and $11 \mathrm{~d}-\mathrm{f}$. Traces of DRX were clearly visible in the EBSD maps as well as in the inverse pole figures (IPF), Figure 11c,f,i,l. Dislocation-free grain nuclei formed firstly at a favourable boundary, which then led to the formation of necklace-type small recrystallised grains along the original grain boundaries of deformation-induced twins, which is known as a common signature of discrete dynamic recrystallisation [78] (see also comprehensive reviews by Humphreys et al. [57] and Sakai et al. [79]). Not surprisingly, the fine grains also nucleated at deformation twin boundaries, as is evidenced indirectly by the appearance of a strong high-angle component in the distribution of angles of misorientation, corresponding to that of extension twins in $\mathrm{Mg}$ (c.f., Figures 5c and 10c). The role of deformation twinning in the formation of fine recrystallised grains is visible in Figure 11e in a more direct way. Fine-grain regions formed in the alloy during DRX did not show signs of twinning activities. As deformation proceeded to $5 \%\left(\varepsilon_{c r}^{A E}\right)$, c.f., Figures $10 \mathrm{~d}$ and $11 \mathrm{~g}-\mathrm{h}$, notable grain coarsening and rounding occurred, giving rise to the increasing fraction of large grains, Figure 10e. The high-angle component in the distribution of misorientation angles decreased drastically, Figure 10f. As a result of these structural transformations, the material restored its ability to deform plastically. Indeed, as the strain increased to $10 \%\left(>\varepsilon_{c r}^{A E}\right)$, the grain size distribution remained almost unchanged (c.f., Figure 10e,h), but twin-related high angle boundaries reappeared in the deformation microstructure again, Figure $10 \mathrm{i}$ and, most notably, Figure 11k. 



Figure 10. The grain structure of the alloy $\mathrm{Mg}-1 \mathrm{Zn}-0.2 \mathrm{Ca}$ alloy $(\mathbf{a}, \mathbf{d}, \mathbf{g})$ and corresponding distributions of the effective grain size $(\mathbf{b}, \mathbf{e}, \mathbf{h})$ and angles of misorientation between grains $(\mathbf{c}, \mathbf{f}, \mathbf{i})$ after testing at $200{ }^{\circ} \mathrm{C}$ and $\dot{\varepsilon}=5 \times 10^{-3} \mathrm{~s}^{-1}$ to $3 \%(\mathbf{a}-\mathbf{c}), 5 \%(\mathbf{d}-\mathbf{f})$, and $10 \%(\mathbf{g}-\mathbf{i})$ strain. 

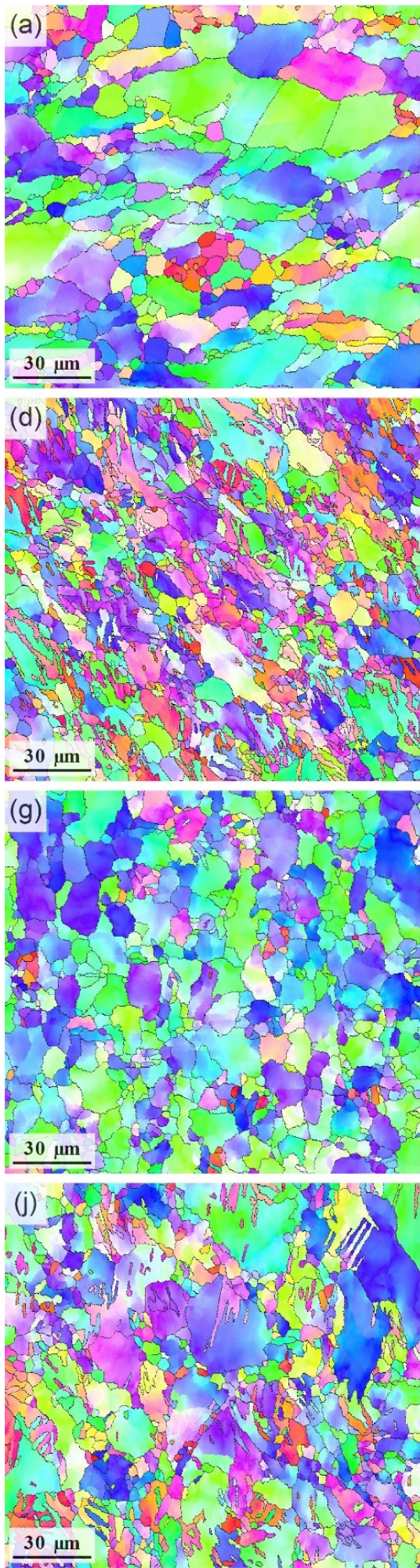
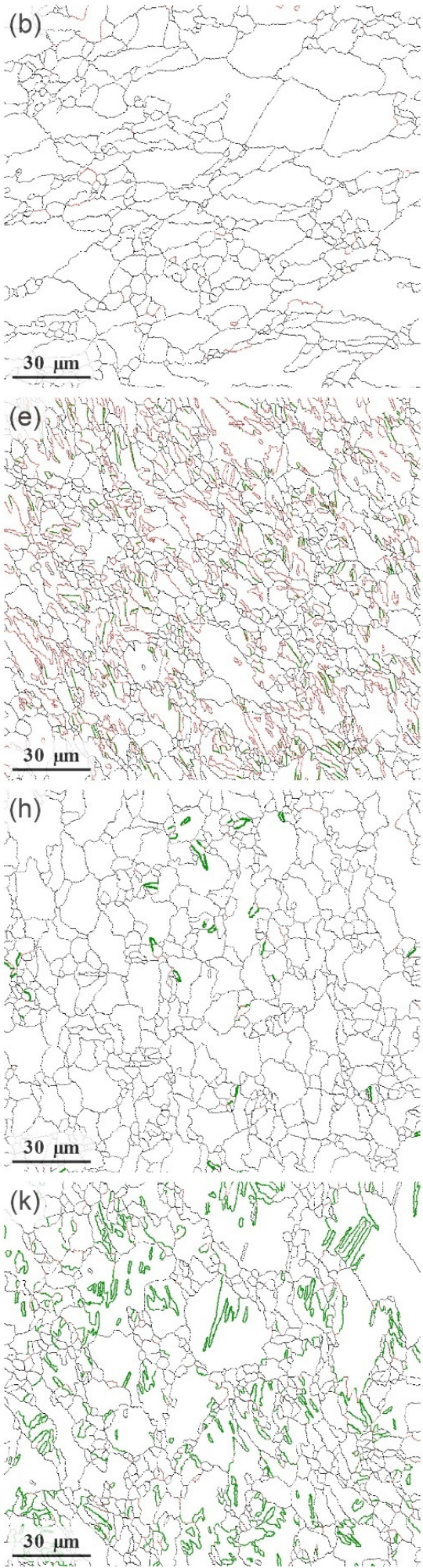

(c)

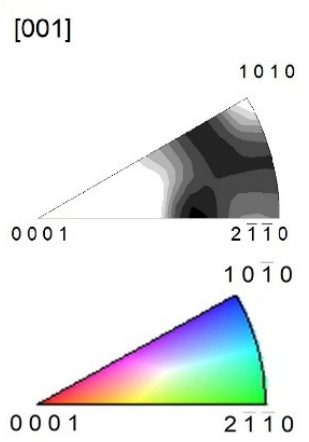

(f)

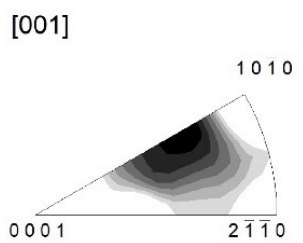

(i)

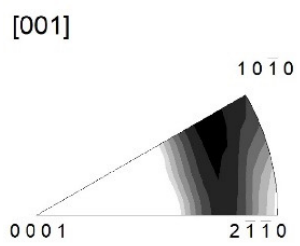

(l)

[001]

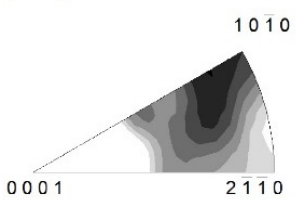

Figure 11. Results of the EBSD analysis of the deformation microstructure for the Mg-1Zn-0.2Ca alloy tested in tension at $200^{\circ} \mathrm{C}$ to different strains (all maps have been obtained for the planes normal to the longitudinal axis of the specimens): (a-c) initial structure $\varepsilon=0,(\mathbf{d}-\mathbf{f}) \varepsilon=3 \%,(\mathbf{g}-\mathbf{i}) \varepsilon=5 \%$, and $(\mathbf{j}-\mathbf{l})$ $\varepsilon=10 \%$; (a,d, $\mathbf{g}, \mathbf{j})$ EBSD maps are coded in IPF colours shown in (c); (b,e, $\mathbf{h}, \mathbf{k})$ show the high-angle grain boundary maps with the highlighted (by the red colour) ranged between 85 and $95^{\circ}$, the tension twins are highlighted by green; $(\mathbf{c}, \mathbf{f}, \mathbf{i}, \mathbf{l})$ IPF pole figures indicating the texture evolution with straining. 
Similar changes in microstructure were observed for other testing schedules listed in Table 2, and, therefore, the described results are considered common and typical.

As has been discussed above, the strain $\varepsilon_{c r}^{A E}$ is likely indicative of the ending of the DRX process when the nucleation of fine grains gives way to grain coarsening, thus regaining the capacity to accommodate plastic strains further. While there is no twinning activity in the small grains, the twins, which tend to nucleate easier at larger grains [80], the twins are supposed to reactivate in the grown grains. This is exactly what is seen in Figure $10 \mathrm{~g}$ (implicitly in the distribution of the angles of misorientation) and Figure 11 (where extension twins are highlighted in the grain boundary EBSD maps). The careful examination of Figure $7 \mathrm{f}$ shows that after $18 \mathrm{~s}$ corresponding approximately to $\varepsilon_{c r}^{A E}$, the rapidly increasing $\mathrm{AE}$ activity was observed due to high amplitude $\mathrm{AE}$ bursts, which are attributed to twinning [81,82]. This is illustrated in Figure 12, where the activity of high-amplitude signals is plotted (red line) together with $E$ and $f_{m}$ as a function of strain. It can be seen that this activity was maximum in the first $8 \mathrm{~s}$ of loading (up to $2 \%$ total strain). Then it decreased sharply, indicating exhaustion of the twinning mechanism. Between 8 and $18 \mathrm{~s}$, the high amplitude transients ceased to appear. The AE median frequency increased, implying that the dislocation slip was a prevailing deformation mode at that time interval. Note that Barnett et al. [70] observed that twinning, which dominated the plastic flow during compression of AZ31 at lower temperatures, gave way to slip governing the plastic flow when the temperature increased. However, after $18 \mathrm{~s}$, the activity of burst signals increased again, which is indicative of the recurrence of the deformation twinning in the recrystallised grains.

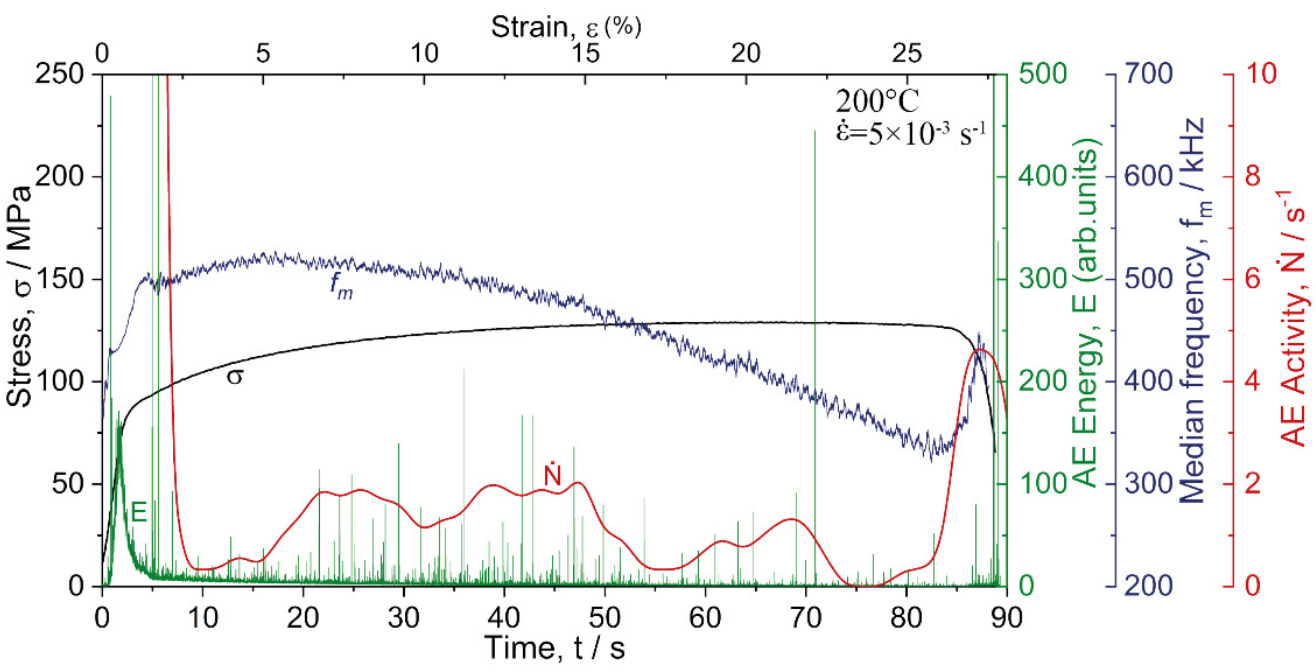

Figure 12. The acoustic emission diagram for the $\mathrm{Mg}-1 \mathrm{Zn}-0.2 \mathrm{Ca}$ alloy was tested at $200{ }^{\circ} \mathrm{C}$ (c.f., Figure $7 \mathrm{f}$ ) with the activity (number of signals per second shown by a red line) of the high-amplitude twinning-related AE bursts superimposed.

\section{Conclusions}

Motivated by the need for a better understanding of the deformation mechanisms underlying the mechanical behaviour of wrought $\mathrm{Mg}$ alloys in a wide range of temperatures and strain rates, we investigated the mechanical response of the low-alloyed fine-grain biomedical magnesium alloy $\mathrm{Mg}-1 \mathrm{Zn}-0.2 \mathrm{Ca}$ (in wt.\%) fabricated via multiaxial isothermal forging and tested in tension with the concomitant measurements of the wideband acoustic emission signal. The following conclusions are drawn. 
1. The common trends towards decreasing strength and increasing ductility were observed with the increasing test temperature; the steepest change occurred at $250{ }^{\circ} \mathrm{C}$.

2. The advanced broadband $\mathrm{AE}$ technique was shown (for the first time to the best of our knowledge) to be well suited for reflecting the changes in the deformation behaviour associated with the dynamic recovery and recrystallisation occurring at elevated temperatures.

3. The evolution of the AE spectral density with plastic strain at elevated temperatures exhibited a specific behaviour of the median frequency, which peaked at a certain strain where dynamic recovery and recrystallisation occurred. This characteristic, strongly non-monotonic behaviour of the AE spectrum, which contrasts to the steady strain dependence at low temperatures, serves as an indicator of the evolution of dynamic recrystallisation towards completeness. In the investigated range of strain rates, the effect of dynamic recrystallisation was observed at $150{ }^{\circ} \mathrm{C}$ and higher.

4. The activity of mechanical twinning decreased with increasing temperature giving priority to dislocation slip. However, as recrystallisation proceeded and freshly nucleated grains grew, and the contribution of the twinning mode to the plastic flow regained and was visible even at elevated temperatures.

5. The proposed methodology based on the modern AE method can be efficiently adapted and applied in both laboratory research and in industrial settings to find the optimised manufacturing conditions for nominally hard to deform magnesium alloys.

Author Contributions: Conceptualisation, D.M. and A.V.; methodology, M.L.; investigation, M.L., A.B. and A.D.; resources, D.M.; writing-original draft preparation, D.M.; writing-review and editing, A.V.; visualisation, M.L., A.D. and A.B.; supervision, D.M.; project administration, D.M.; funding acquisition, D.M. All authors have read and agreed to the published version of the manuscript.

Funding: This research was funded by the Russian Science Foundation through grant-in-aid No. 20-19-00585.

Institutional Review Board Statement: Not applicable.

Informed Consent Statement: Not applicable.

Data Availability Statement: Data are available from the corresponding author upon reasonable request.

Acknowledgments: The authors are thankful to A. Polunin (TSU) for his skilful help with XRD measurements.

Conflicts of Interest: The authors declare no conflict of interest.

\section{References}

1. Atrens, A.; Song, G.-L.; Liu, M.; Shi, Z.; Cao, F.; Dargusch, M.S. Review of Recent Developments in the Field of Magnesium Corrosion. Adv. Eng. Mater. 2015, 17, 400-453. [CrossRef]

2. Witte, F.; Hort, N.; Feyerabend, F.; Vogt, C. Magnesium $(\mathrm{Mg})$ corrosion: A challenging concept for degradable implants. In Corrosion of Magnesium Alloys; Song, G.-L., Ed.; Woodhead Publishing: Sawston, UK, 2011; Chapter 10; pp. 403-425. [CrossRef]

3. $\quad$ Erinc, M.; Sillekens, W.H.; Mannens, R.G.T.M.; Werkhoven, R.J. Applicability of existing magnesium alloys as biomedical implant materials. In Magnesium Technology; Nyberg, E.A., Agnew, S.R., Neelameggham, N.R., Pekguleryuz, M.O., Eds.; TMS (The Minerals and Materials Society): Warrendale, PA, USA, 2009; pp. 209-214.

4. Chen, S.; Smith, C.E.; Xu, Z.; Sankar, J. Development of biodegradable Mg-Zn-Ca alloys for biomedical applications. In Proceedings of the ASME International Mechanical Engineering Congress and Exposition, Proceedings (IMECE), Vancouver, BC, Canada, 12-18 November 2010; pp. 43-48.

5. Riaz, U.; Shabib, I.; Haider, W. The current trends of Mg alloys in biomedical applications-A review. J. Biomed. Mater. Res. Part B Appl. Biomater. 2019, 107, 1970-1996. [CrossRef] [PubMed]

6. Chen, Y.; Dou, J.; Yu, H.; Chen, C. Degradable magnesium-based alloys for biomedical applications: The role of critical alloying elements. J. Biomater. Appl. 2019, 33, 1348-1372. [CrossRef]

7. Herber, V.; Okutan, B.; Antonoglou, G.; Sommer, N.G.; Payer, M. Bioresorbable Magnesium-Based Alloys as Novel Biomaterials in Oral Bone Regeneration: General Review and Clinical Perspectives. J. Clin. Med. 2021, 10, 1842. [CrossRef] [PubMed]

8. Amani, S.; Faraji, G. Processing and Properties of Biodegradable Magnesium Microtubes for Using as Vascular Stents: A Brief Review. Met. Mater. Int. 2019, 25, 1341-1359. [CrossRef] 
9. Singh Raman, R.K.; Jafari, S.; Harandi, S.E. Corrosion fatigue fracture of magnesium alloys in bioimplant applications: A review. Eng. Fract. Mech. 2015, 137, 97-108. [CrossRef]

10. Gunde, P.; Hänzi, A.C.; Sologubenko, A.S.; Uggowitzer, P.J. High-strength magnesium alloys for degradable implant applications. Mater. Sci. Eng. A 2011, 528, 1047-1054. [CrossRef]

11. Hänzi, A.C.; Sologubenko, A.S.; Uggowitzer, P.J. Design strategy for new biodegradable Mg-Y-Zn alloys for medical applications. Int. J. Mater. Res. 2009, 100, 1127-1136. [CrossRef]

12. Hofstetter, J.; Becker, M.; Martinelli, E.; Weinberg, A.M.; Mingler, B.; Kilian, H.; Pogatscher, S.; Uggowitzer, P.J.; Löffler, J.F. High-Strength Low-Alloy (HSLA) Mg-Zn-Ca Alloys with Excellent Biodegradation Performance. JOM 2014, 66, 566-572. [CrossRef]

13. Hofstetter, J.; Martinelli, E.; Pogatscher, S.; Schmutz, P.; Povoden-Karadeniz, E.; Weinberg, A.M.; Uggowitzer, P.J.; Löffler, J.F. Influence of trace impurities on the in vitro and in vivo degradation of biodegradable $\mathrm{Mg}-5 \mathrm{Zn}-0.3 \mathrm{Ca}$ alloys. Acta Biomater. 2015, 23, 347-353. [CrossRef]

14. Hofstetter, J.; Martinelli, E.; Weinberg, A.M.; Becker, M.; Mingler, B.; Uggowitzer, P.J.; Löffler, J.F. Assessing the degradation performance of ultrahigh-purity magnesium in vitro and in vivo. Corros. Sci. 2015, 91, 29-36. [CrossRef]

15. Hofstetter, J.; Rüedi, S.; Baumgartner, I.; Kilian, H.; Mingler, B.; Povoden-Karadeniz, E.; Pogatscher, S.; Uggowitzer, P.J.; Löffler, J.F. Processing and microstructure-property relations of high-strength low-alloy (HSLA) Mg-Zn-Ca alloys. Acta Mater. 2015, 98, 423-432. [CrossRef]

16. Gu, X.; Zheng, Y.; Cheng, Y.; Zhong, S.; Xi, T. In vitro corrosion and biocompatibility of binary magnesium alloys. Biomaterials 2009, 30, 484-498. [CrossRef] [PubMed]

17. Hillis, J.E. The effects of heavy metal contamination on magnesium corrosion performance. SAE Trans. 1983, 92, 830362-830691. [CrossRef]

18. Estrin, Y.; Vinogradov, A. Extreme grain refinement by severe plastic deformation: A wealth of challenging science. Acta Mater. 2013, 61, 782-817. [CrossRef]

19. Ralston, K.D.; Birbilis, N. Effect of grain size on corrosion: A review. Corrosion 2010, 66, 075005-075005-13. [CrossRef]

20. Orlov, D.; Ralston, K.D.; Birbilis, N.; Estrin, Y. Enhanced corrosion resistance of Mg alloy ZK60 after processing by integrated extrusion and equal channel angular pressing. Acta Mater. 2011, 59, 6176-6186. [CrossRef]

21. Vasilev, E.; Linderov, M.; Nugmanov, D.; Sitdikov, O.; Markushev, M.; Vinogradov, A. Fatigue Performance of Mg-Zn-Zr Alloy Processed by Hot Severe Plastic Deformation. Metals 2015, 5, 2316-2327. [CrossRef]

22. Doležal, P.; Zapletal, J.; Fintová, S.; Trojanová, Z.; Greger, M.; Roupcová, P.; Podrábský, T. Influence of processing techniques on microstructure and mechanical properties of a biodegradable Mg-3Zn-2Ca Alloy. Materials 2016, 9, 880. [CrossRef]

23. Galiyev, A.; Kaibyshev, R.; Gottstein, G. Correlation of plastic deformation and dynamic recrystallization in magnesium alloy ZK60. Acta Mater. 2001, 49, 1199-1207. [CrossRef]

24. Nugmanov, D.; Sitdikov, O.; Markushev, M. Grain Refinement in the Magnesium Alloy ZK60 During Multi-Step Isothermal Forging. Mater. Sci. Forum 2015, 830-831, 7-10. [CrossRef]

25. Al-Samman, T.; Gottstein, G. Dynamic recrystallization during high temperature deformation of magnesium. Mater. Sci. Eng. A 2008, 490, 411-420. [CrossRef]

26. Avvari, M.; Narendranath, S.; Nayaka, H.S. A review on wrought magnesium alloys processed by equal channel angular pressing. Int. J. Mater. Prod. Technol. 2015, 51, 139-164. [CrossRef]

27. Huang, H.; Zhang, J. Microstructure and mechanical properties of AZ31 magnesium alloy processed by multi-directional forging at different temperatures. Mater. Sci. Eng. A 2016, 674, 52-58. [CrossRef]

28. Ding, X.; Zhao, F.; Shuang, Y.; Ma, L.; Chu, Z.; Zhao, C. Characterization of hot deformation behavior of as-extruded AZ31 alloy through kinetic analysis and processing maps. J. Mater. Processing Technol. 2020, 276, 116325. [CrossRef]

29. Zhang, K.; Zheng, J.-H.; Shao, Z.; Pruncu, C.; Turski, M.; Guerini, C.; Jiang, J. Experimental investigation of the viscoplastic behaviours and microstructure evolutions of AZ31B and Elektron 717 Mg-alloys. Mater. Des. 2019, 184, 108160. [CrossRef]

30. Aliyari, S.; Fatemi, S.M.; Miresmaeili, S.M. Effects of solution treatment on high temperature deformation behavior of extruded Mg-0.35Y-2.17Nd-0.36Zr biomedical alloy. Trans. Nonferrous Met. Soc. China 2019, 29, 1842-1853, English Edition. [CrossRef]

31. Kaviani, M.; Ebrahimi, G.R.; Ezatpour, H.R. Improving the mechanical properties and biocorrosion resistance of extruded Mg-Zn-Ca-Mn alloy through hot deformation. Mater. Chem. Phys. 2019, 234, 245-258. [CrossRef]

32. Chaman-Ara, M.; Ebrahimi, G.R.; Ezatpour, H.R. Deformation behavior and processing maps of Mg-Zn-Y alloy containing I phase at elevated temperatures. Trans. Nonferrous Met. Soc. China 2018, 28, 629-641. [CrossRef]

33. Nascimento, L.; Yi, S.; Bohlen, J.; Fuskova, L.; Letzig, D.; Kainer, K.U. High cycle fatigue behaviour of magnesium alloys. Procedia Eng. 2010, 2, 743-750. [CrossRef]

34. Vinogradov, A.; Orlov, D.; Danyuk, A.; Estrin, Y. Effect of grain size on the mechanisms of plastic deformation in wrought $\mathrm{Mg}-\mathrm{Zn}-\mathrm{Zr}$ alloy revealed by acoustic emission measurements. Acta Mater. 2013, 61, 2044-2056. [CrossRef]

35. Remy, L. Kinetics of f.c.c. deformation twinning and its relationship to stress-strain behaviour. Acta Metall. 1978, $26,443-451$. [CrossRef]

36. Lou, X.Y.; Li, M.; Boger, R.K.; Agnew, S.R.; Wagoner, R.H. Hardening evolution of AZ31B Mg sheet. Int. J. Plast. 2007, $23,44-86$. [CrossRef]

37. Yoo, M. Slip, twinning, and fracture in hexagonal close-packed metals. Met. Trans. A 1981, 12, 409-418. [CrossRef] 
38. Kocks, U.F.; Westlake, D.G. Importance of twinning for ductility of hcp polycrystals. Trans. Metall. Soc. AIME 1967, $239,1107$.

39. Taylor, G.I. Plastic strain in metals. J. Inst. Met. 1938, 62, 307-324.

40. Carpenter, S.R.; Heiple, C.R. Acoustic Emission Generated by Dislocation Mechanisms during the Deformation of Metals. In Fundamentals of Acoustic Emission; Ono, K., Ed.; Univeristy of California: Los Angeles, CA, USA, 1979; pp. 49-104.

41. Eitzen, D.G.; Wadley, H.N.G. Acoustic-Emission-Establishing the Fundamentals. J. Res. Natl. Bur. Stand. 1984, 89, 75-100. [CrossRef]

42. Wadley, H.N.G.; Mehrabian, R. Acoustic emission for materials processing: A review. Mater. Sci. Eng. 1984, 65, $245-263$. [CrossRef]

43. Zhang, B.P.; Wang, Y.; Geng, L. Research on Mg-Zn-Ca Alloy as Degradable Biomaterial, Biomaterials—Physics and Chemistry. In Biomaterials; Pignatello, R., Ed.; InTechOpen: London, UK, 2011. [CrossRef]

44. Lu, Y. Microstructure and Degradation Behaviour of Mg-Zn(-Ca) Alloys. Ph.D. Thesis, University of Birmingham, Birmingham, UK, 2014.

45. Kulyasova, O.B.; Islamgaliev, R.K.; Zhao, Y.; Valiev, R.Z. Enhancement of the Mechanical Properties of an Mg-Zn-Ca Alloy Using High-Pressure Torsion. Adv. Eng. Mater. 2015, 17, 1738-1741. [CrossRef]

46. Merson, D.; Brilevsky, A.; Myagkikh, P.; Tarkova, A.; Prokhorikhin, A.; Kretov, E.; Frolova, T.; Vinogradov, A. The Functional Properties of Mg-Zn-X Biodegradable Magnesium Alloys. Materials 2020, 13, 544. [CrossRef]

47. Merson, D.; Brilevsky, A.; Myagkikh, P.; Markushev, M.; Vinogradov, A. Effect of deformation processing of the dilute Mg1Zn-0.2Ca alloy on the mechanical properties and corrosion rate in a simulated body fluid. Lett. Mater. 2020, 10, 217-222 [CrossRef]

48. Vinogradov, A.; Vasilev, E.; Kopylov, V.I.; Linderov, M.; Brilevesky, A.; Merson, D. High Performance Fine-Grained Biodegradable Mg-Zn-Ca Alloys Processed by Severe Plastic Deformation. Metals 2019, 9, 186. [CrossRef]

49. Martynenko, N.S.; Anisimova, N.Y.; Rybalchenko, O.V.; Kiselevskiy, M.V.; Rybalchenko, G.; Straumal, B.; Temralieva, D.; Mansharipova, A.T.; Kabiyeva, A.O.; Gabdullin, M.T.; et al. Rationale for Processing of a Mg-Zn-Ca Alloy by Equal-Channel Angular Pressing for Use in Biodegradable Implants for Osteoreconstruction. Crystals 2021, 11, 1381. [CrossRef]

50. Yang, L.; Liu, G.; Ma, L.; Zhang, E.; Zhou, X.; Thompson, G. Effect of iron content on the corrosion of pure magnesium: Critical factor for iron tolerance limit. Corros. Sci. 2018, 139, 421-429. [CrossRef]

51. Liu, M.; Uggowitzer, P.J.; Nagasekhar, A.V.; Schmutz, P.; Easton, M.; Song, G.-L.; Atrens, A. Calculated phase diagrams and the corrosion of die-cast Mg-Al alloys. Corros. Sci. 2009, 51, 602-619. [CrossRef]

52. Nugmanov, D.R.; Sitdikov, O.S.; Markushev, M.V. Microstructure evolution in MA14 magnesium alloy under multi-step isothermal forging. Lett. Mater. 2011, 1, 213-216. [CrossRef]

53. Markushev, M.V.; Nugmanov, D.R.; Sitdikov, O.; Vinogradov, A. Structure, texture and strength of Mg-5.8Zn-0.65Zr alloy after hot-to-warm multi-step isothermal forging and isothermal rolling to large strains. Mater. Sci. Eng. A 2018, 709, 330-338. [CrossRef]

54. Linderov, M.; Vasilev, E.; Merson, D.; Markushev, M.; Vinogradov, A. Corrosion Fatigue of Fine Grain Mg-Zn-Zr and Mg-Y-Zn Alloys. Metals 2018, 8, 20. [CrossRef]

55. Lazarev, S.; Mozgovoi, A.; Vinogradov, A.; Lazarev, A.; Shvedov, A. Electromagnetic method of elastic wave excitation for calibration of acoustic emission sensors and apparatus. J. Acoust. Emiss. 2009, 27, 215-223.

56. Vinogradov, A.; Nadtochiy, M.; Hashimoto, S.; Miura, S. Acoustic-Emission Spectrum and Its Orientation Dependence in Copper Single-Crystals. Mater. Trans. JIM 1995, 36, 496-503. [CrossRef]

57. Humphreys, F.J.; Hatherly, M. Recrystallization and Related Annealing Phenomena, 2nd ed.; Elsevier: Amsterdam, The Netherlands, 2004.

58. Oh, J.C.; Ohkubo, T.; Mukai, T.; Hono, K. TEM and 3DAP characterization of an age-hardened Mg-Ca-Zn alloy. Scr. Mater. 2005, 53, 675-679. [CrossRef]

59. Nie, J.F.; Muddle, B.C. Precipitation hardening of Mg-Ca(-Zn) alloys. Scr. Mater. 1997, 37, 1475-1481. [CrossRef]

60. Heiple, C.R.; Carpenter, S.H. Acoustic Emission Produced by Deformation of Metals and Alloys-A review: Part I and II. J. Acoust. Emiss. 1987, 6, 177-237.

61. Vinogradov, A.; Yasnikov, I.S.; Estrin, Y. Stochastic dislocation kinetics and fractal structures in deforming metals probed by acoustic emission and surface topography measurements. J. Appl. Phys. 2014, 115, 233506. [CrossRef]

62. Vinogradov, A.; Lazarev, A. Continuous acoustic emission during intermittent plastic flow in $\alpha$-brass. Scr. Mater. 2012, 66, 745-748. [CrossRef]

63. McCrory, J.P.; Vinogradov, A.; Pearson, M.R.; Pullin, R.; Holford, K.M. Acoustic Emission Monitoring of Metals. In Acoustic Emission Testing: Basics for Research-Applications in Engineering; Grosse, C.U., Ohtsu, M., Aggelis, D.G., Shiotani, T., Eds.; Springer International Publishing: Cham, Switzerland, 2022; pp. 529-565. [CrossRef]

64. Vinogradov, A.; Orlov, D.; Danyuk, A.; Estrin, Y. Deformation mechanisms underlying tension-compression asymmetry in magnesium alloy ZK60 revealed by acoustic emission monitoring. Mater. Sci. Eng. A 2015, 621, 243-251. [CrossRef]

65. Vinogradov, A.; Heczko, M.; Mazánová, V.; Linderov, M.; Kruml, T. Kinetics of cyclically-induced mechanical twinning in $\gamma$-TiAl unveiled by a combination of acoustic emission, neutron diffraction and electron microscopy. Acta Mater. 2021, $212,116921$. [CrossRef]

66. Vinogradov, A.; Lazarev, A.; Linderov, M.; Weidner, A.; Biermann, H. Kinetics of deformation processes in high-alloyed cast transformation-induced plasticity/twinning-induced plasticity steels determined by acoustic emission and scanning electron microscopy: Influence of austenite stability on deformation mechanisms. Acta Mater. 2013, 61, 2434-2449. [CrossRef] 
67. Linderov, M.; Segel, C.; Weidner, A.; Biermann, H.; Vinogradov, A. Deformation mechanisms in austenitic TRIP/TWIP steels at room and elevated temperature investigated by acoustic emission and scanning electron microscopy. Mater. Sci. Eng. A 2014, 597, 183-193. [CrossRef]

68. Vinogradov, A.V.; Patlan, V.; Hashimoto, S. Spectral analysis of acoustic emission during cyclic deformation of copper single crystals. Philos. Mag. A 2001, 81, 1427-1446. [CrossRef]

69. Agnew, S.R. Deformation mechanisms of magnesium alloys. In Advances in Wrought Magnesium Alloys: Fundamentals of Processing, Properties and Applications; Bettles, C., Barnett, M., Eds.; Woodhead Publishing: Sawston, UK, 2012; pp. 63-104. [CrossRef]

70. Barnett, M.R.; Keshavarz, Z.; Beer, A.G.; Atwell, D. Influence of grain size on the compressive deformation of wrought Mg-3Al1Zn. Acta Mater. 2004, 52, 5093-5103. [CrossRef]

71. Kleiner, S.; Uggowitzer, P.J. Mechanical anisotropy of extruded Mg-6\% Al-1\% Zn alloy. Mater. Sci. Eng. A 2004, 379, 258-263. [CrossRef]

72. Koike, J. Enhanced deformation mechanisms by anisotropic plasticity in polycrystalline Mg alloys at room temperature. Met. Mater. Trans. A 2005, 36, 1689-1696. [CrossRef]

73. Chino, Y.; Mabuchi, M. Enhanced stretch formability of Mg-Al-Zn alloy sheets rolled at high temperature (723K). Scr. Mater. 2009, 60, 447-450. [CrossRef]

74. Chapuis, A.; Driver, J.H. Temperature dependency of slip and twinning in plane strain compressed magnesium single crystals. Acta Mater. 2011, 59, 1986-1994. [CrossRef]

75. Hutchinson, W.B.; Barnett, M.R. Effective values of critical resolved shear stress for slip in polycrystalline magnesium and other hcp metals. Scr. Mater. 2010, 63, 737-740. [CrossRef]

76. Jain, A.; Agnew, S.R. Modeling the temperature dependent effect of twinning on the behavior of magnesium alloy AZ31B sheet. Mater. Sci. Eng. A 2007, 462, 29-36. [CrossRef]

77. Chapuis, A.; Liu, Q. Investigating the temperature dependency of plastic deformation in a Mg-3Al-1Zn alloy. Mater. Sci. Eng. A 2018, 725, 108-118. [CrossRef]

78. Zhang, H.K.; Xiao, H.; Fang, X.W.; Zhang, Q.; Logé, R.E.; Huang, K. A critical assessment of experimental investigation of dynamic recrystallization of metallic materials. Mater. Des. 2020, 193, 108873. [CrossRef]

79. Sakai, T.; Belyakov, A.; Kaibyshev, R.; Miura, H.; Jonas, J.J. Dynamic and post-dynamic recrystallization under hot, cold and severe plastic deformation conditions. Prog. Mater. Sci. 2014, 60, 130-207. [CrossRef]

80. Vinogradov, A.; Vasilev, E.; Merson, D.; Estrin, Y. A Phenomenological Model of Twinning Kinetics. Adv. Eng. Mater. 2017, 19, 1600092. [CrossRef]

81. Vinogradov, A.; Vasilev, E.; Seleznev, M.; Máthis, K.; Orlov, D.; Merson, D. On the limits of acoustic emission detectability for twinning. Mater. Lett. 2016, 183, 417-419. [CrossRef]

82. Vinogradov, A.; Máthis, K. Acoustic Emission as a Tool for Exploring Deformation Mechanisms in Magnesium and Its Alloys In Situ. JOM 2016, 68, 3057-3062. [CrossRef] 